\title{
THE
}

1998

\section{Feeding Mechanism of the Atlantic Guitarfish Rhinobatos Lentiginosus: Modulation of Kinematic and Motor Activity}

Cheryl D. Wilga

University of Rhode Island, cwilga@uri.edu

Philip J. Motta

Follow this and additional works at: https://digitalcommons.uri.edu/bio_facpubs

Creative Commons License

(c) (i) (8)

This work is licensed under a Creative Commons Attribution-Noncommercial 3.0 License

\section{Citation/Publisher Attribution}

Wilga, C.D. and P.J. Motta. 1998. The feeding mechanism of the Atlantic guitarfish Rhinobatos lentiginosus: Modulation of kinematic and motor activity. Journal of Experimental Biololgy, 201:

3167-3183.

Available at http://jeb.biologists.org/content/201/23/

3167.full.pdf+html?sid=edcb6850-82b4-4016-a2a3-c574512a0511

JEB1725

This Article is brought to you for free and open access by the Biological Sciences at DigitalCommons@URI. It has been accepted for inclusion in Biological Sciences Faculty Publications by an authorized administrator of DigitalCommons@URI. For more information, please contact digitalcommons-group@uri.edu. 


\title{
FEEDING MECHANISM OF THE ATLANTIC GUITARFISH RHINOBATOS LENTIGINOSUS: MODULATION OF KINEMATIC AND MOTOR ACTIVITY
}

\author{
CHERYL D. WILGA* AND PHILIP J. MOTTA \\ Department of Biological Science, University of South Florida, Tampa, FL 33620, USA \\ *Present address: Department of Ecology and Evolutionary Biology, University of California at Irvine, Irvine, CA 95697-2525, USA \\ (e-mail: cwilga@uci.edu)
}

Accepted 16 September; published on WWW 10 November 1998

\begin{abstract}
Summary
The kinematics and muscle activity pattern of the head and jaws during feeding in the Atlantic guitarfish Rhinobatos lentiginosus are described and quantified using high-speed video and electromyography to test hypotheses regarding the conservation and modulation of the feeding mechanism. Prey is captured by the guitarfish using suction. Suction capture, bite manipulation and suction transport behaviors in the guitarfish are similar to one another in the relative sequence of kinematic and motor activity, but can be distinguished from one another by variation in absolute muscle activation time, in the

feeding behaviors and has not been described previously in elasmobranchs. The mechanism of upper jaw protrusion in the guitarfish differs from that described in other elasmobranchs. Muscle function and motor pattern during feeding are similar in the plesiomorphic cranial muscles in the guitarfish and the spiny dogfish probably because of their shared ancestral morphology. Modulation in recruitment of jaw and hyoid depressor muscles among feeding behaviors in the guitarfish may be a consequence of duplication of muscles and decoupling of the jaws and hyoid apparatus in batoids.
\end{abstract} presence or absence of muscle activity and in the duration of muscle activity. A novel compression transport behavior was observed that is strikingly different from the other

Key words: Atlantic guitarfish, Rhinobatos lentiginosus, kinematics, motor pattern, feeding, jaw protrusion, elasmobranch.

\section{Introduction}

Recently, increasing attention has been given to the study of feeding behavior in sharks (Elasmobranchii) (Moss, 1972, 1977; Tricas and McCosker, 1984; Frazzetta and Prange, 1987; Frazzetta, 1988, 1994; Ferry-Graham, 1997; Wilga, 1997; Motta et al. 1997; Wilga and Motta, 1998). These studies have contributed greatly to our understanding of feeding mechanisms in sharks and aquatic vertebrates in general. In contrast, rays, skates and guitarfishes [Elasmobranchii: Galea + Squalea (Batoidea)], which comprise more than half $(57-58 \%)$ of the total number of elasmobranch species (Compagno, 1977; de Carvalho, 1996), have received comparatively little attention.

Evidence based on morphological characteristics has led systematists to propose that batoids arose from squalean sharks, one of the two main lineages of shark, in the early Jurassic (Fig. 1) (Carroll, 1988; DE Carvalho, 1996; McEachran et al. 1996; Shirai, 1996). This hypothesis requires the secondary loss of the craniopalatine articulation and a switch from the orbitostylic jaw suspension of squaleans to the euhyostylic jaw suspension of batoids (Gregory, 1904; Maisey, 1980). Accordingly, the mandibular, the hyoid and even the branchial arches of batoids are highly modified from those of sharks (Shirai, 1996). The position of the mandibular arch has changed from anteriorly directed in sharks to ventrally directed in batoids.
The musculature of the cranium, jaws and hyoid arch has become more complex in batoids compared with that of sharks, with the development of several new muscles (Compagno, 1977; Moss, 1977; Miyake et al. 1992; McEachran et al. 1996; Shirai, 1996).

Studies of feeding behavior have revealed that a basic kinematic feeding sequence appears to be conserved in carcharhiniform, lamniform and squaliform sharks (Tricas and McCosker, 1984; Frazzetta and Prange, 1987; Ferry-Graham, 1997; Motta et al. 1997; Wilga, 1997; Wilga and Motta, 1998). However, some sharks are capable of consistently varying details of kinematic activity depending on feeding mode (capture versus transport, ram versus suction) or prey type (Ferry-Graham, 1997; Motta et al. 1997; Wilga, 1997; Wilga and Motta, 1998). In addition, the relative sequence of activity in the cranial muscles during feeding in two carcharhiniform sharks, the lemon shark Negaprion brevirostris and the bonnethead shark Sphyrna tiburo, appears to be quite consistent despite the high individual variation (Motta et al. 1997; Wilga, 1997). In contrast, some jaw retractor muscles may be active during the expansive phase or the recovery phase depending on feeding behavior in the spiny dogfish Squalus acanthias (capture, manipulation and transport) (FerryGraham, 1997; Motta et al. 1997; Wilga, 1997; Wilga and 


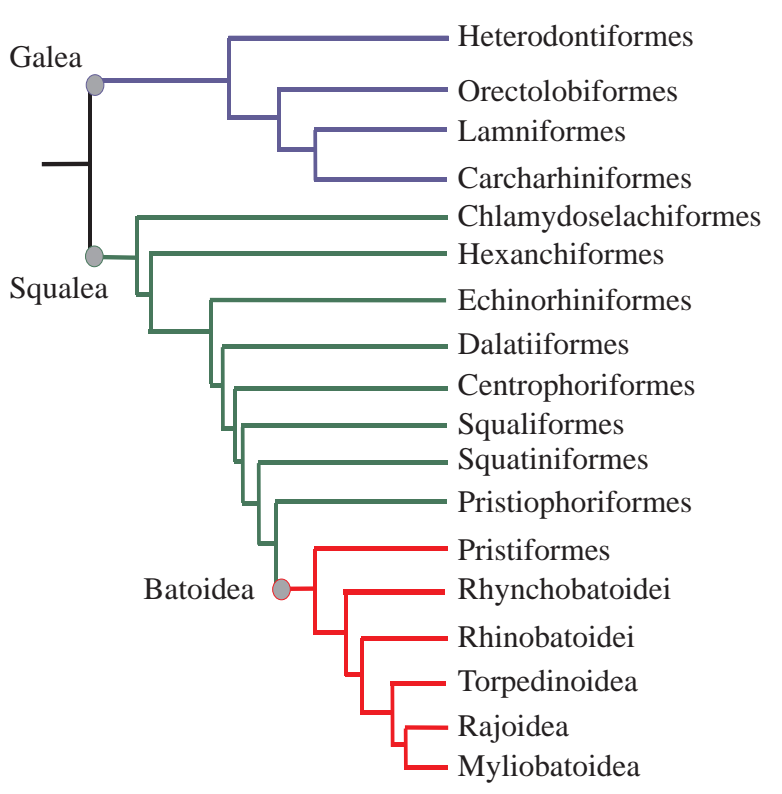

Fig. 1. Elasmobranch phylogeny according to Shirai (1996). Galea, Squalea and Batoidea clades are indicated by blue, green and red lines, respectively.

Motta, 1998). However, it is not known whether the feeding mechanism in batoids is conserved or whether they also demonstrate variation in kinematics and motor activity.

The Atlantic guitarfish Rhinobatos lentiginosus (Batoidea: Rhinobatoidei) was chosen as a study animal to provide a basis for interpreting batoid feeding mechanisms in the light of our current understanding of shark feeding mechanisms. Many morphological characters of guitarfish are intermediate between those of sharks and rays (Compagno, 1977; Shirai, 1996; McEachran et al. 1996) and may provide insight into the evolution of the feeding apparatus of sharks and rays. Batoids, including $R$. lentiginosus, possess a number of morphological specializations that may allow modulation of the ancestral shark feeding mechanism (Gregory, 1904; Maisey, 1980; McEachran et al. 1996; Shirai, 1996). Phylogenetically, rhinobatoids occupy an important position as the sister-group to the clade containing most of the skates and rays (Torpedinoidea + Rajoidea + Myliobatoidea) (Shirai, 1996). Finally, studies on the feeding mechanism in such a large and diverse group as batoids are needed to increase our understanding of the evolution of feeding mechanisms in elasmobranchs.

The feeding mechanism has yet to be described for any species of batoid. One goal of this paper is to test the hypothesis that the kinematics and motor pattern are distinct among prey capture, prey manipulation and prey transport behaviors in R. lentiginosus, as observed in some sharks. The second goal is to compare the kinematics and motor pattern of the plesiomorphic cranial muscles during feeding in $R$. lentiginosus with those of a squalean shark, the spiny dogfish Squalus acanthias, to test whether they have been conserved throughout evolution.

\section{Materials and methods}

Research specimens

Specimens of the Atlantic guitarfish Rhinobatos lentiginosus collected from the Gulf of Mexico off Longboat Key, Sarasota, Florida, USA, were obtained from and held at Mote Marine Laboratory. The guitarfish were maintained in a 14001 semicircular tank provided with continuous fresh flowing sea water at approximately $25^{\circ} \mathrm{C}$ and fed shrimp (Panaeus sp.) three times a week. Quartz-halogen floodlights $(3000 \mathrm{~W})$ were used during feeding to acclimatize the animal to the experimental conditions. All experiments were conducted within 14-30 days after capture. Anatomical dissections were made on four fresh dead $R$. lentiginosus specimens $(52.4-63.5 \mathrm{~cm}$ total length, TL) to describe the feeding apparatus. Muscle terminology follows that of Luther (1909), Edgeworth (1935), Marion (1905) and Miyake et al. (1992).

\section{High-speed video recording and analyses}

For 3 days prior to the experiments, food was withheld from the guitarfish. During the experiments, video recordings were made through a $0.5 \mathrm{~m} \times 1.7 \mathrm{~m}$ acrylic window set into the side of the tank. The guitarfish were filmed during the feeding experiments using two NAC 200 high-speed video cameras at 200 field $\mathrm{s}^{-1}$. A split screen recorded two camera views: one camera was directed at the window to film the lateral view, while the second camera was directed at a mirror placed at $45^{\circ}$ to the floor of the tank in order to film the ventral view simultaneously. The experimental tank was illuminated by $3000 \mathrm{~W}$ quartz-halogen floodlights.

The guitarfish depresses its pectoral fins against the substratum while feeding, and if the body is positioned parallel to the filming plane, as is usually required for these types of experiments, then the jaws will not be visible because the pectoral fin obscures the jaws. Therefore, only feeding events in which the jaws were visible, i.e. at an angle that is anterolateral to the lateral camera, were used in the analyses. The two cameras were set to the same magnification. Cranial movements were measured from the video images recorded during feeding in five guitarfish (range 50.5-63.5 cm TL): 42 prey captures (mean, five per individual), 28 bite manipulations (mean, six per individual) and 25 transports (mean, five per individual) were subsequently analyzed. The timing of 13 kinematic events was analyzed fieldby-field by digitizing or by visually locating the video field containing the event of interest for capture, manipulation and transport behaviors. These variables include: start of lower jaw depression; maximum lower jaw depression; start of lower jaw elevation; complete closure of the jaws; start of cranial depression; maximum cranial depression; end of cranial elevation; start of upper jaw protrusion; maximum upper jaw protrusion; start of upper jaw retraction; end of upper jaw retraction; start of prey movement (the field in which the prey starts to move); and end of prey movement (the field in which the prey stops moving or is no longer visible). The total duration of each feeding event was calculated from the start of lower jaw movement to the end of upper jaw retraction.

Maximum gape distance and maximum upper jaw 
protrusion distance were measured to test the contribution that protrusion of the upper jaw makes to reducing the gape. The magnitudes of these two kinematic variables were digitized field-by-field using the following points for prey capture. Maximum gape distance $(\mathrm{cm})$ was calculated as the length of the hypotenuse of a right-angled triangle with two sides consisting of the vertical distance between the lower jaw tip and the upper jaw tip in the lateral view ( $y$ axis) and the horizontal distance between the lower jaw tip and the upper jaw tip in the ventral view ( $x$ axis). Using the hypotenuse for the gape distance adjusts for the off-lateral angle of the fish to the camera. Maximum upper jaw protrusion distance $(\mathrm{cm})$ was calculated using the vertical distance between the tip of the upper jaw and the eye minus the resting distance.

The ram-suction index (RSI) was calculated to analyze the relative contribution of predator and prey movements during prey capture. The RSI is a relative measure of the distance that the predator and prey move during a prey capture behavior:

$$
\mathrm{RSI}=\left(D_{\text {predator }}-D_{\text {prey }}\right) /\left(D_{\text {predator }}+D_{\text {prey }}\right),
$$

where $D$ is the distance moved (Norton and Brainerd, 1993). In a pure ram feeding event, the predator moves towards the prey while the prey remains stationary, resulting in an RSI of +1 . In contrast, in a pure suction feeding event, the prey is moved towards the predator and the predator remains stationary, resulting in an RSI of -1 . Thus, the RSI is a continuum that ranges from +1 to -1 . The RSI was calculated for 18 captures by five guitarfish (mean, four per individual) using the eye of the predator and the point on the prey closest to the predator as kinematic landmarks. Since only dead prey were used, this index reflects the distance moved by the predator and the distance the prey is moved as a result of the predator's influence, such as being drawn towards the predator by suction.

\section{Electromyography and analyses}

Electromyograms were recorded simultaneously with the video experiments described above to document the sequence of muscle activation relative to kinematic events. Electromyograms were recorded using bipolar electrodes, each of which was constructed from $1.8 \mathrm{~m}$ lengths of $0.0057 \mathrm{~cm}$ diameter insulated alloy wire. Approximately $1 \mathrm{~mm}$ at the end of each wire was stripped of insulation and bent backwards to form a hook. A third piece of hooked insulated wire $3 \mathrm{~cm}$ long was placed alongside each bipolar electrode to allow verification of electrode placement in case the electrode was inadvertently pulled out. The electrodes were implanted in nine cranial muscles using 26 gauge hypodermic needles. The guitarfish were anesthetized during surgery using $0.065 \mathrm{~g} \mathrm{l}^{-1}$ tricaine methanesulfonate (MS222). The guitarfish were intubated and maintained on this dosage of anesthetic during surgery using the recirculated seawater/anesthetic solution. Following electrode implantation, all the electrode wires were glued together to form a cable and sutured to the skin just posterior to the synarcual (fused cervical vertebrae). The surgical procedure took approximately $30 \mathrm{~min}$, after which the guitarfish was returned to the experimental tank and intubated with fresh sea water until it had recovered enough to commence swimming (5-15 min). Feeding trials began after normal swimming behavior had been observed for at least $1 \mathrm{~h}$ post-recovery and continued until the guitarfish was satiated. The guitarfish were offered headless shrimp approximately $2 \mathrm{~cm}$ long, which were dropped into the tank to facilitate anterolateral video recordings.

The electrode wires from the guitarfish were attached to differential amplifiers set at a gain of 1000, bandpass 100-3000 $\mathrm{Hz}$ with $60 \mathrm{~Hz}$ notch filter. Seven channels (six muscles, one synchronizer signal) were recorded simultaneously. Signals were monitored simultaneously on a four-channel oscilloscope and an eight-channel thermal array recorder and recorded on a pulse code modulator that multiplexed the signals to a videocassette recorder. The electromygram (EMG) tracings and video recordings were synchronized using a synchronizer unit that emits a preprogrammed repeating pulse pattern simultaneously to one channel of the tape recorder and to lightemitting diode strobes that are recorded by the video camera.

At the termination of each experiment, the shark was killed with an overdose of MS-222 according to the University of South Florida and Mote Marine Laboratory Institutional Animal Care and Use Committee guidelines. The positions of the electrodes were verified by dissection, and total body length was measured to the nearest millimeter.

Motor activity patterns were analyzed during feeding in 30 prey capture (mean, six per individual), 28 bite manipulation (mean, six per individual) and 25 transport (mean, five per individual) events. Electromyograms were recorded from nine muscles that had previously been implicated in feeding behavior (Marion, 1905; Daniel, 1922; Miyake et al. 1992), including the levator hyomandibularis, anterior quadratomandibularis, levator palatoquadrati, medial preorbitalis, coracomandibularis, depressor mandibularis, depressor hyomandibularis, coracohyomandibularis and coracohyoideus. Recordings were made from these muscles in all five individuals except for the depressor mandibularis (four individuals), coracomandibularis (two individuals) and coracohyoideus (one individual).

Analog electromyographic signals for individual feeding trials were digitized using Spike 2 software at a sampling rate of $8333 \mathrm{~Hz}$. Electromyograms for each muscle for each feeding event were analyzed for burst duration and timing relative to the start of lower jaw movement as determined by the pattern of synchronization marks on the video images and EMG tracings.

\section{Interspecific comparison}

Data on the spiny dogfish Squalus acanthias from a previous study (Wilga and Motta, 1998) were used for an interspecific comparison to test for conservation of kinematic and motor patterns. The following kinematic variables were compared: start of cranial depression; maximum cranial depression; start of cranial elevation, maximum cranial elevation; maximum lower jaw depression; complete closure of the jaws; start of upper jaw protrusion; maximum upper jaw protrusion; and end of upper jaw retraction. The onset and duration of activity in select plesiomorphic muscles (Miyake et al. 1992; Shirai, 
1996) were compared; these muscle include the coracomandibularis, quadratomandibularis, preorbitalis, levator palatoquadrati and levator hyomandibularis.

\section{Statistical tests}

A mixed-model two-way analysis of variance (ANOVA) using type III sums of squares was performed separately on the EMG and kinematic variables from the capture, manipulation, suction and compression transport data for the guitarfish comparisons. Individual is a random main effect and behavior is a fixed main effect. Behavior was tested by the individual $\times$ behavior interaction (Hicks, 1982). A mixed-model nested ANOVA using type III sums of squares was performed separately on the EMG and kinematic variables for the interspecific comparison between the guitarfish and the dogfish. Species is a fixed main effect, with the individual random effect nested within species. Species was tested by the individual (nested within species) effect (Hicks, 1982). Maximum gape minus maximum upper jaw protrusion distance was compared with maximum gape distance in a paired $t$-test to test the contribution that protrusion of the upper jaw makes to reducing the gape.

The following variables were tested: time of onset and duration of EMG activity; and start, maximum and end of kinematic events relative to the start of lower jaw movement. The coracohyoideus and coracomandibularis muscles were not tested statistically because of the low sample numbers. If a difference was detected by ANOVA using Bonferroni adjusted $P$-values, a Student-Newman-Keuls (SNK) multiplecomparison test $(P<0.05)$ was performed. The data were tested for homogeneous variances using the Burr-Foster $Q$-test $(P<0.01)$ and for normal distribution using the Kolmogorov-Smirnov test $(P<0.05)$. If the data did not meet these assumptions of parametric statistics, they were logtransformed and then rechecked to confirm that the assumptions were satisfied. Statistical tests were performed using SAS (version 6.12) statistical software.

\section{Terminology}

Feeding behaviors in fishes are typically categorized as prey capture, prey manipulation and prey transport. Prey capture is the initial acquisition of the prey and can be described as consisting of two behaviors, the attack and the strike (Cook, 1996). The attack begins when the predator accelerates towards the prey from the pre-attack resting position and ends when the head and jaws return to the pre-attack resting position. The strike is a subset of the attack and begins when the mouth of the predator opens and ends when the mouth closes. Prey manipulation is processing of the prey in order to reduce, disable or reposition it. Prey transport is movement of the prey from the jaws to the esophagus for swallowing.

Prey capture, prey manipulation and prey transport behaviors can be further subdivided into four phases that partition the cranial movements and motor activity into functional phases during feeding (Liem, 1978; Lauder, 1985). The preparatory phase is defined as the period prior to mouth opening in which compression of the buccal cavity may take place and is absent in many fishes. The expansive phase is characterized by mouth opening and extends from the start of lower jaw depression to maximum lower jaw depression. Protrusion of the upper jaw in bony fishes takes place during this phase. The compressive phase is characterized by mouth closing and extends from maximum lower jaw depression to complete closure of the jaws. In the cartilaginous fishes, upper jaw protrusion takes place during this phase. The recovery phase is characterized by retraction of the closed jaws and extends from jaw closure to the return of the cranial elements to their resting position.

\section{Results \\ Jaw suspension}

Batoids have a euhyostylic jaw suspension in which the hyomandibula is the sole support for the jaws, the anterior end of the palatoquadrate does not articulate with the cranium and the ceratohyal-basihyal complex is disconnected from the hyomandibula and attached to the first branchial arch (Fig. 2) (Gregory, 1904; Maisey, 1980). The long axis of the jaws is oriented transversely with a ventral gape in batoids; in contrast, in sharks, the long axis of the jaws is oriented longitudinally with an anterior gape. The symphysis between the palatoquadrate and mandible is relatively loose and allows each side of the jaw to move from an angle of approximately $180^{\circ}$ to each other in the resting position (the medial ends of the palatoquadrate or mandible are end to end in a straight line) to approximately $90^{\circ}$ to each other during maximum jaw protrusion (the medial ends of the palatoquadrate or mandible are nearly perpendicular to each other) (Fig. 3).

\section{Myology}

The cranial muscles of $R$. lentiginosus studied in this paper can be divided into axial (epaxialis), mandibular (quadratomandibularis, preorbitalis, levator palatoquadrati), hyoid (depressor mandibularis, levator hyomandibularis, depressor hyomandibularis, levator rostri, depressor rostri) and hypobranchial (coracomandibularis, coracohyoideus, coracoarcualis, coracohyomandibularis) muscle plates on the basis of embryological origin. The levator hyomandibularis originates on the otic capsule and inserts onto the dorsal surface of the hyomandibula (Fig. 4A). The levator palatoquadrati originates on the postorbital process and inserts onto the dorsal surface of the palatoquadrate (Fig. 4A-C). The preorbitalis medialis and lateralis extend from the nasal region (ventral and dorsal surfaces respectively) and insert onto the mandible (Fig. 4A,B). The quadratomandibularis consists of four divisions (anterior, medial, posterior and deep), which extend from the lateral surface of the palatoquadrate to the lateral surface of the mandible (Fig. 4A-C). The depressor mandibularis originates on the superficial hypobranchial raphe (not shown) overlying the coracomandibularis and inserts onto the posterior surface of the mandible (Fig. 4B). The depressor hyomandibularis also originates on the superficial hypobranchial raphe and inserts onto the ventral surface of the hyomandibula (Fig. 4B). The coracomandibularis originates on the deep hypobranchial raphe and inserts onto the posterior 

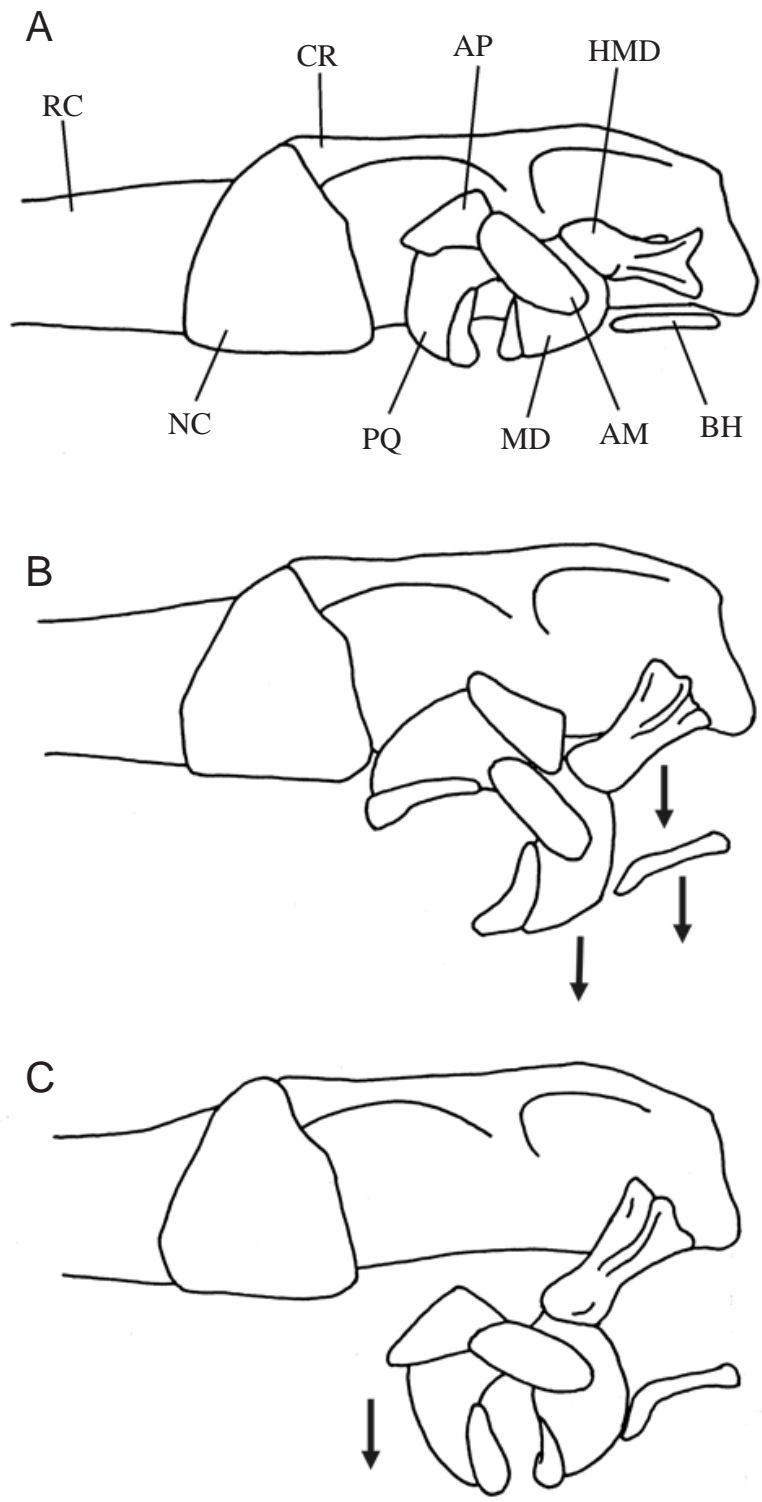

Fig. 2. Left lateral view of the cranium, hyoid arch and jaws of a $63.5 \mathrm{~cm}$ total length female. Resting position (A); depression of the lower jaw, hyomandibula and basihyal open the mouth (B); maximally protruded position of the upper jaw (C). Arrows show movement of cartilages. AM, adductor mandibulae process of mandible; AP, adductor mandibulae process of palatoquadrate; $\mathrm{BH}$, basihyal; $\mathrm{CR}$, cranium; HMD, hyomandibula; $\mathrm{MD}$, mandible or lower jaw; NC, nasal capsule; $\mathrm{PQ}$, palatoquadrate or upper jaw; RC, rostral cartilage.

surface of the mandible (Fig. 4B). The coracohyoideus originates on the deep hypobranchial raphe and inserts onto the posterior surface of the basihyal (hyoid) (Fig. 4C). The coracohyomandibularis originates on the superficial and deep hypobranchial raphe and pericardium and inserts onto the ventral surface of the hyomandibula medial to the depressor hyomandibularis (Fig. 4C).

Since the preorbitalis and quadratomandibularis contain more than one division and the number of amplifiers available

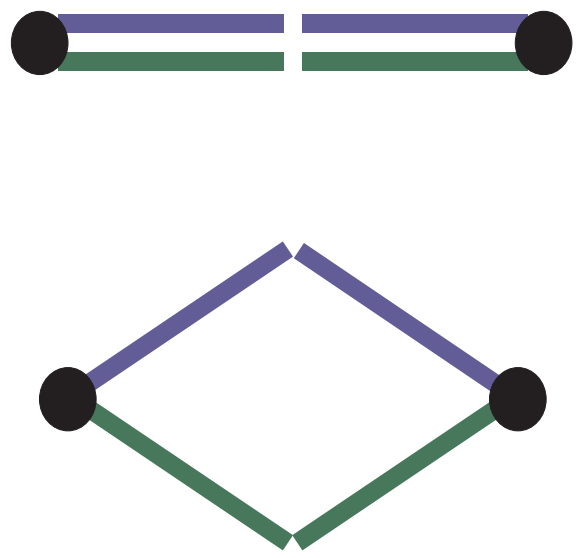

Fig. 3. Schematic diagram of the anteroventral view of the upper (blue lines) and lower (green lines) jaws with the mouth in the closed (upper) and the open (lower) position. Black circles represent the jaw joint, and the open space between the bars represents the symphysis.

was limited, only one division of each of these muscles was implanted. The medial division of the preorbitalis was implanted with electrodes since its position is similar to that of the single preorbitalis in Squalus acanthias. The anterior division of the quadratomandibularis was implanted since it is the largest adductor of the jaws.

The following muscles were not implanted but are described here in order to aid in the interpretation of the anatomical figures. The coracoarcualis is very thin, originates on the anterior surface of the coracoid bar and inserts onto the deep hypobranchial raphe (Fig. 4A,B). The coracoarcualis was not implanted because of its lack of any direct connection to the hyoid. The depressor rostri originates on the superficial hypobranchial raphe and extends anterolaterally to insert onto the ventral surface of the rostrum (Fig. 4A). The anterior fibers of the epaxialis insert onto the otic capsule (Fig. 4C). The levator rostri originates on the epaxialis and extends anterolaterally to insert onto the dorsal surface of the rostrum (Fig. 4C).

\section{Kinematics}

A guitarfish begins an attack by rapidly approaching the prey, then using its body to immobilize the prey against the substratum. The guitarfish then elevates its body slightly and repositions itself over the prey using the pectoral fins, pelvic fins, rostrum and tail to maneuver its mouth close enough to engulf the prey. During this repositioning phase, the rostrum, the tail and the edges of the pectoral and pelvic fins of the guitarfish are pressed against the substratum, allowing the body to form a tent over the prey and presumably preventing its escape. This attack behavior is observed with newly caught guitarfish and becomes less pronounced after the fish have become accustomed to non-elusive prey in captivity. In other words, the behavior appears less vigorous or less rapid, but is still present and is an important component of the attack; it does not appear to alter the strike phase of the feeding event. 


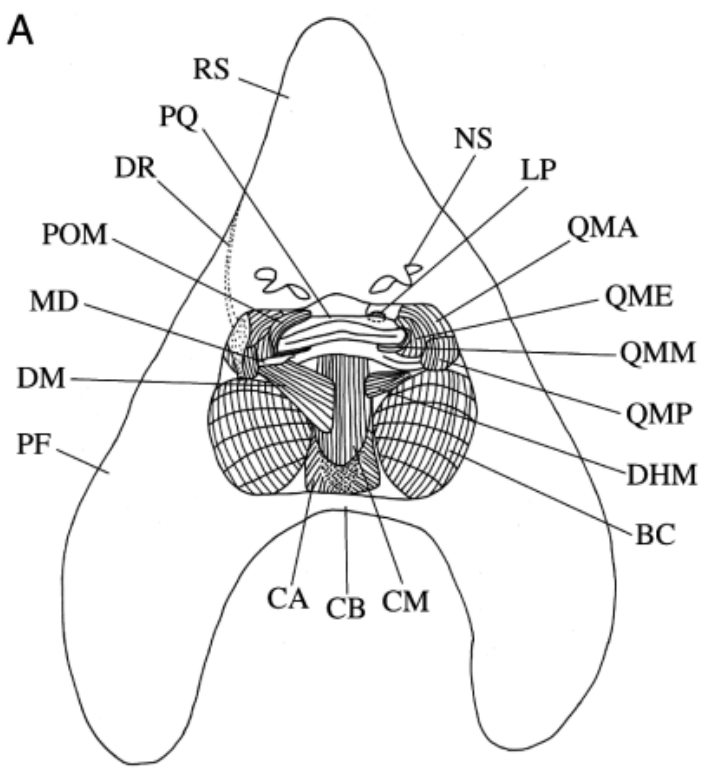

During the strike phase, the guitarfish captures pieces of shrimp using suction in which rapid expansion of the orobranchial cavity draws the prey into the mouth by suction inflow. The RSI of $-0.11 \pm 0.05$ (mean \pm S.E.M., $N=5$; range -0.71 to 0.56 ) indicates that a relatively greater contribution of suction than of ram was used to capture the prey. The cranium is depressed well before the lower jaw is depressed during prey capture in the guitarfish and is usually kept depressed until after prey transport. The cranium may be elevated or depressed slightly throughout the feeding event; no consistent pattern was detected. Although a preparatory phase consisting of motor activity was found (see section on motor activity patterns), the corresponding skeletal movements were not visible in the video recordings.

The expansive phase begins with the start of lower jaw depression as the guitarfish approaches the prey (Figs 5, 6A). As the lower jaw is depressed, the orobranchial chamber is rapidly expanded and the prey is drawn into the mouth by suction inflow. Movement of the prey begins shortly before maximum gape and ends shortly after maximum gape. Maximum hyoid depression could not be determined because depression of the pectoral fins and jaws obscured hyoid movements. However, maximum hypobranchial depression appears to take place towards the end of the expansive phase and the beginning of the compressive phase. The compressive phase begins with elevation of the lower jaw and the beginning of upper jaw protrusion. Maximum upper jaw protrusion is attained just prior to complete closure of the jaws. Upper jaw protrusion (mean maximum $0.81 \pm 0.10 \mathrm{~cm}, N=5$ ) makes a significant $(t$-test, $P<0.0001)$ contribution towards reducing the gape (mean maximum $1.41 \pm 0.16 \mathrm{~cm}, N=5$ ), leaving the remaining $43 \%$ of the gape for elevation of the lower jaw to close. During the recovery phase, the upper and lower jaws are elevated back to their resting position.

After capture of the prey, multiple manipulation events composed of the following various behaviors are performed on the prey. The prey may be expelled completely from the mouth and then recaptured either by suction completely into the orobranchial cavity or by catching it between the jaws. The

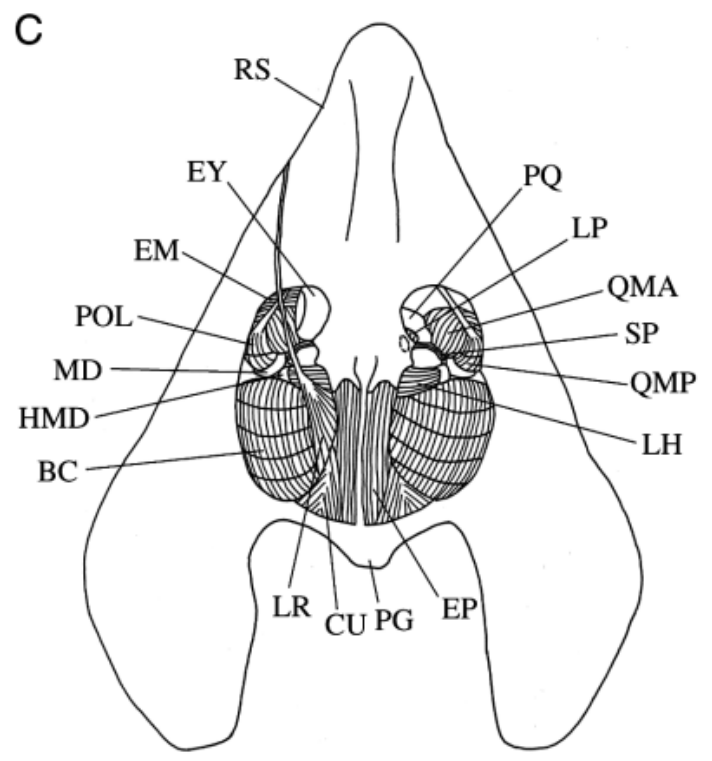

Fig. 4. Cranial muscles illustrated in superficial ventral (A), deep ventral (B) and dorsal (C) views of a $63.5 \mathrm{~cm}$ total length female with the skin over the cranial muscles and depressor rostri muscle removed and the muscle fiber direction indicated. The right side of each diagram shows the superficial muscles and the left side shows the deep muscles. $\mathrm{BC}$, branchial constrictors; $\mathrm{BH}$, basihyal; $\mathrm{CA}$, coracoarcualis; $\mathrm{CB}$, coracoid bar; $\mathrm{CH}$, coracohyoideus; $\mathrm{CHM}$, coracohyomandibularis; CM, coracomandibularis; CU, cucullaris; DHM, depressor hyomandibularis; DM, depressor mandibularis; DR, depressor rostri (insertion is dotted, origin is similar to the deeper DM); EM, ethmoideo-parethmoidalis; EP, epaxialis; EY, eye; HMD, hyomandibula; LH, levator hyomandibularis; LP, levator palatoquadrati; LR, levator rostri; MD, mandible (lower jaw); NS, nostril; PG, pectoral girdle; PF, pectoral fin; POL, preorbitalis lateralis; POM, preorbitalis medial; PQ, palatoquadrate (upper jaw); QMA, quadratomandibularis anterior; QME, quadratomandibularis deep; QMM, quadratomandibularis medial; QMP, quadratomandibularis posterior; RP, raphe overlying pericardium; RS, rostrum; SP, spiracularis. 


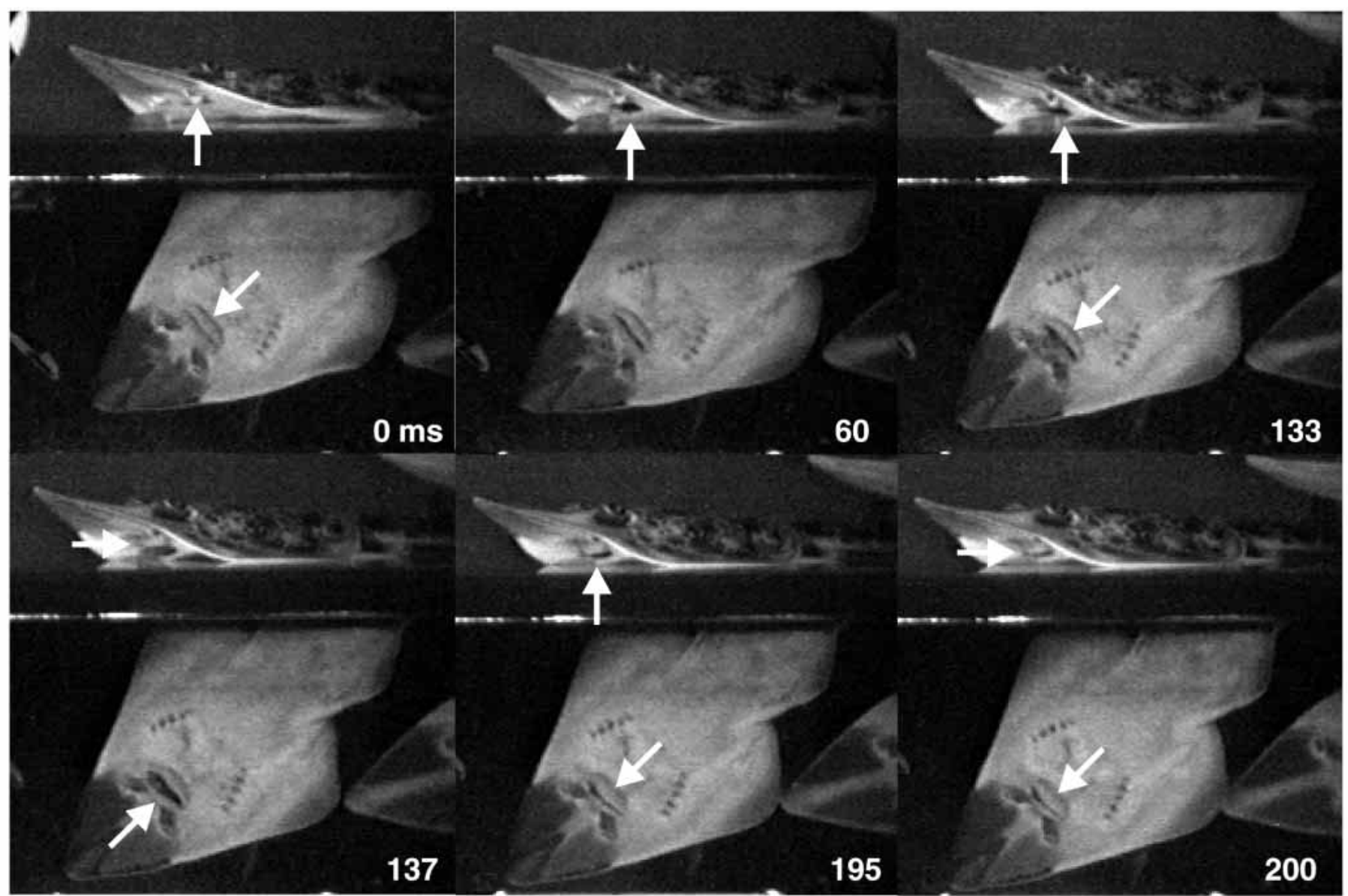

Fig. 5. Lateral (top) and ventral (bottom) video images of a representative suction prey capture. 0 ms, start of lower jaw depression; $60 \mathrm{ms,}$ symphysial angle decreases; $133 \mathrm{~ms}$, maximum lower jaw depression; $137 \mathrm{~ms}$, start of upper jaw protrusion; $195 \mathrm{~ms}$, minimum symphysial angle; $200 \mathrm{~ms}$, maximum upper jaw protrusion and lower jaw elevation. Arrows point to the jaw positions described above.

prey may be expelled from the orobranchial cavity to be caught between the jaws. The jaws may simply open and close onto the prey already contained in the mouth for repositioning or biting-crushing. Bite manipulations are composed of similar cranial movements to those of capture (Fig. 6B), except that the prey is already contained between the jaws prior to the start of the event and the prey is re-grasped between the jaws at the end of the event.

After prey processing, the prey is transported from the jaws to the esophagus. Prey transport is divided into two distinct phases in the guitarfish, a suction transport phase followed by a compression transport phase. During suction transport, as the mouth is opened, the prey is moved posteriorly by suction towards the pharynx. The cranial movements during suction transport are similar to those during suction capture (compare Fig. 6C with Fig. 6A), except that the prey is already between the jaws at the start of the event.

Compression transport is a novel behavior that takes place after suction transport and appears to involve a compression pump mechanism. Jaw movements during compression transport differ markedly from those during capture, manipulation and suction transport behaviors. The cranium is elevated well before the first compression transport event and remains elevated throughout the event. Compression transport lacks an expansive phase and begins with the compressive phase, in which both the upper and lower jaws are elevated rapidly from the resting position towards the cranium (Fig. 6D). The compressive phase ends at maximum elevation of the upper and lower jaws. Both the upper and lower jaws are then returned to their resting position during the recovery phase. Although the prey is not visible at this time, compression transport may act to push the prey from the pharynx to the esophagus.

Statistical analysis of the kinematics of cranial movements reveals many differences among prey capture, bite manipulation, suction transport and compression transport behaviors (Table 1). Nearly all the kinematic events occur later during suction captures than during the other feeding behaviors, indicating that suction capture has a longer duration than the other behaviors. The main difference among the behaviors is the earlier start of lower jaw depression, lower jaw elevation and upper jaw protrusion during suction transport and during manipulation than during capture. The mouth does not open during compression transport, rather the jaws are first retracted or elevated towards the cranium and then returned to their resting position. Movement of the prey begins earlier during suction transports than during suction captures. 
Fig. 6. Synchronized mean of kinematic and motor patterns during suction prey capture (A), bite manipulation (B), suction transport (C) and compression transport (D) events. The top diagram shows a suction capture sequence with arrows indicating the approximate phase of events. Gray bars represent LJ depression, UJ protrusion or start of prey movement; white bars represent LJ elevation or UJ retraction, with error bars of 1 S.E.M. Motor activity is represented by black bars whose ends indicate the onset and duration with error bars of 1 S.E.M. The percentage occurrence of electromyogram bursts in the muscle is indicated if activity did not occur in every event. Colored regions indicate feeding phases: pink, preparatory phase; blue, expansive phase (mouth opening); green, compressive phase (mouth closing); yellow, recovery phase (return to resting position). LJ, lower jaw depression, lower jaw elevation; PM, start of prey movement into mouth; QM, anterior quadratomandibularis activity; PO, medial preorbitalis activity; UJ, upper jaw protrusion, upper jaw retraction; other abbreviations as in Fig. 4.

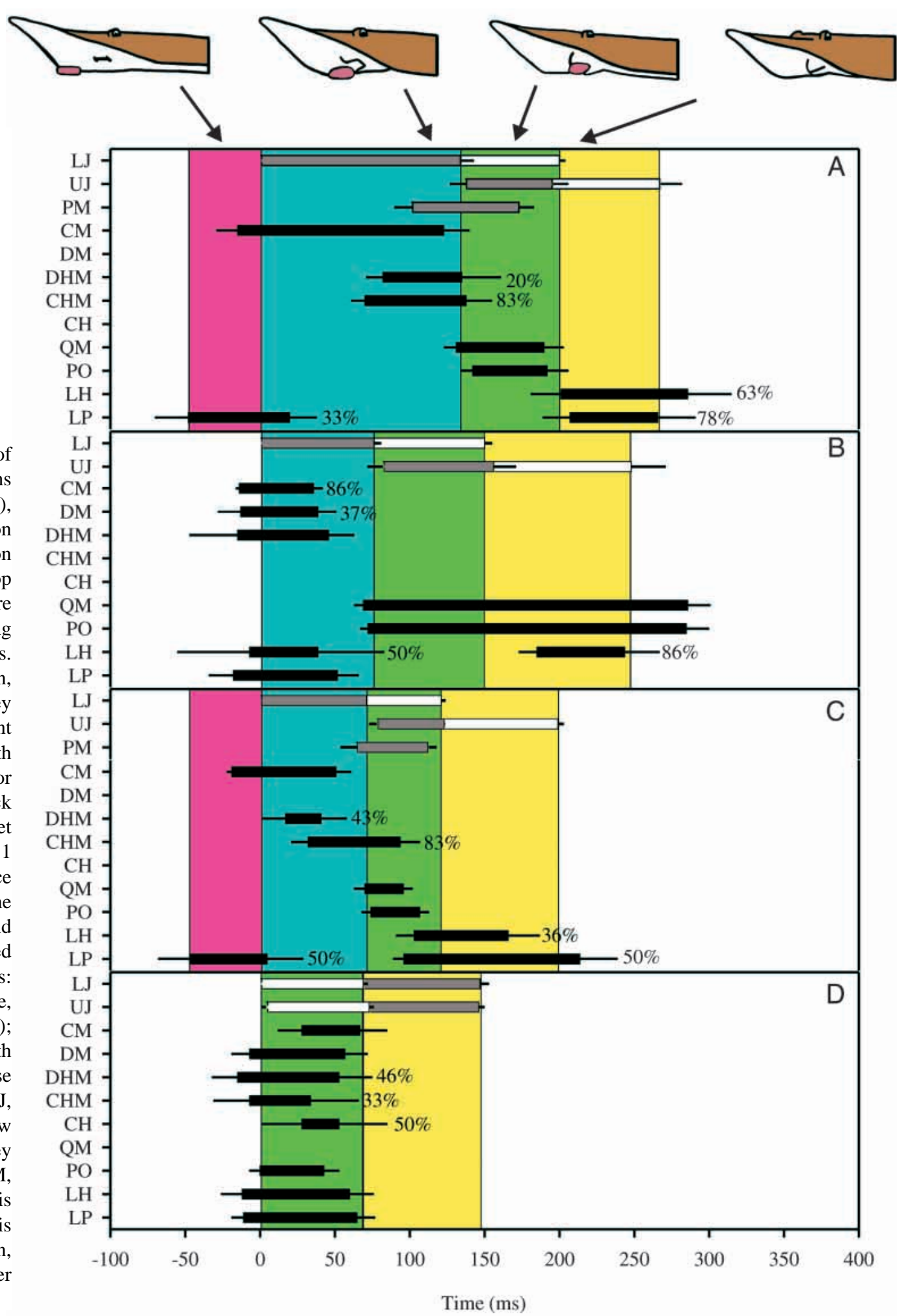

The only kinematic differences found in the interspecific analysis of the guitarfish and the spiny dogfish were restricted to cranial movements (Table 2).

\section{Motor activity patterns}

A preparatory phase is often present during suction capture and suction transport behaviors in which the levator palatoquadrati muscle is active prior to the start of lower jaw depression (Fig. 6A, see also representative EMG tracings in Fig. 7). Retraction of the upper jaw at this time was not observed in the kinematic analyses, possibly because the distance moved was too small to be detected by the methods used. 


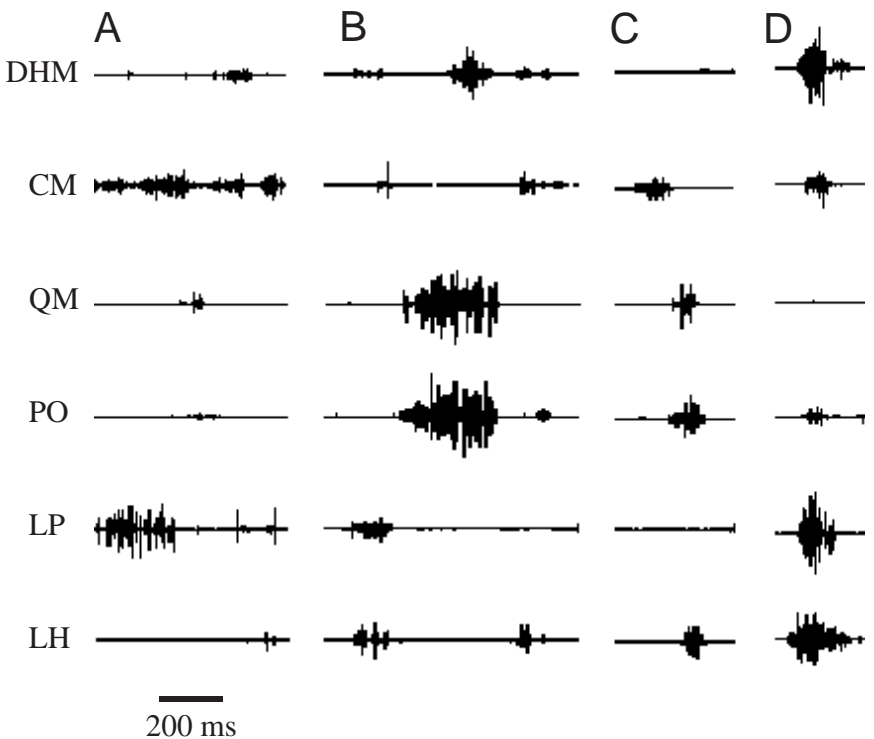

Fig. 7. Electromyographic profile of six muscles during a representative suction capture (A), bite manipulation (B), suction transport (C) and compression transport (D) event. Abbreviations as in Figs 4 and 6.

The coracomandibularis is the first muscle activated during the expansive phase, and activity occurs during depression of the lower jaw. Approximately midway through lower jaw depression, activity in the coracohyomandibularis and depressor hyomandibularis muscles begins, and activity continues until maximum lower jaw depression. The quadratomandibularis and the preorbitalis are both active during lower jaw elevation and upper jaw protrusion. Finally, the levator hyomandibularis and levator palatoquadrati are active during upper jaw retraction after jaw closure.
The motor pattern during bite manipulation differs from that during suction capture in several ways (Fig. 6B). The depressor mandibularis and the depressor hyomandibularis assist the coracomandibularis in depressing the lower jaw. The levator palatoquadrati is primarily active during mouth opening rather than during jaw retraction, while the levator hyomandibularis is active during both phases. The preorbitalis and quadratomandibularis have extremely long activity durations and are active until well after the end of upper jaw retraction.

The duration of motor activity is shorter during suction transport, otherwise the motor pattern is similar to that of suction capture (Fig. 6C). In contrast, the motor activity pattern during compression transport is distinct from that of all other feeding behaviors. A rapid burst of simultaneous activity occurs during jaw elevation in all the cranial muscles except the quadratomandibularis (Fig. 6D). Motor activity then ends at maximum jaw elevation, after which the jaws relax to the resting position.

Statistical analysis of motor activity during suction capture, bite manipulation, suction transport and compression transport reveals many differences among these behaviors (Table 3). Generally, the onset of motor activity occurs later during capture than during manipulation and transport. Coracomandibularis activity occurs later during compression transport than during the other behaviors in the two individuals in which this muscle was successfully implanted. In addition, the duration of activity in the primary jaw depressor muscle, the coracomandibularis, is longest during suction captures in these two individuals. The duration of activity in the jaw-closing muscles (quadratomandibularis and preorbitalis) is greatest during bite manipulations.

Statistical analysis of the mandibular, hyoid and hyomandibular depressors show several differences in the onset of activity dependent on feeding behavior. The depressor mandibularis is active during all compression

Table 1. Statistical variables and results of ANOVAs on the kinematic variables during suction capture (C), bite manipulation $(M)$, suction transport $(S)$ and compression transport $(T)$ behaviors in Rhinobatos lentiginosus

\begin{tabular}{|c|c|c|c|c|c|c|}
\hline Kinematic variable & Capture & Manipulation & $\begin{array}{l}\text { Suction } \\
\text { transport }\end{array}$ & $\begin{array}{l}\text { Compression } \\
\text { transport }\end{array}$ & P-value & SNK \\
\hline Cranial depression start & $-50 \pm 10$ & NP & NP & NP & & \\
\hline Prey movement start & $101 \pm 12$ & NP & $64 \pm 8$ & NP & $0.0001 *$ & $\mathrm{C}>\mathrm{S}$ \\
\hline Lower jaw depression maximum & $133 \pm 10$ & $75 \pm 6$ & $70 \pm 4$ & $146 \pm 5$ & $0.0042^{*}+$ & $\mathrm{C}, \mathrm{T}>\mathrm{M}, \mathrm{S}$ \\
\hline Lower jaw elevation start & $138 \pm 10$ & $80 \pm 6$ & $75 \pm 4$ & 0 & $0.0004 *$ & $\mathrm{C}>\mathrm{M}, \mathrm{S}>\mathrm{T}$ \\
\hline Cranial depression maximum & $161 \pm 14$ & NP & NP & NP & & \\
\hline Prey movement end & $176 \pm 10$ & NP & $111 \pm 8$ & NP & $0.0013^{*}$ & $\mathrm{C}>\mathrm{S}$ \\
\hline Jaw closure complete & $200 \pm 11$ & $149 \pm 12$ & $120 \pm 5$ & NP & $0.0020 *$ & $\mathrm{C}>\mathrm{M}>\mathrm{S}$ \\
\hline Upper jaw retraction start & $203 \pm 11$ & $148 \pm 16$ & $128 \pm 4$ & $4 \pm 1$ & $0.0001 *$ & $\mathrm{C}>\mathrm{M}, \mathrm{S}>\mathrm{T}$ \\
\hline Upper jaw retraction end & $274 \pm 15$ & $247 \pm 21$ & $198 \pm 3$ & $73 \pm 4$ & $0.0001 *, \ddagger$ & $\mathrm{C}, \mathrm{M}>\mathrm{S}>\mathrm{T}$ \\
\hline Cranial elevation end & $287 \pm 36$ & $\mathrm{NP}$ & NP & NP & & \\
\hline
\end{tabular}

Values are means \pm S.E.M. (in ms), from 42 captures, 28 manipulations, 25 suction transports and 25 compression transports from 5 individuals.

Significant behavior, * and individual, $\ddagger$, effects at Bonferroni value of $P=0.005$; NP, indicates events in which that kinematic event is not present; SNK, results of Student-Newman-Keuls multiple-comparisons test. 


\section{C. D. Wilga AND P. J. MotTA}

Table 2. Statistical variables and results of the nested ANOVA for the interspecific kinematic analysis

\begin{tabular}{lccc}
\hline Kinematic variable & $\begin{array}{c}\text { Species } \\
P \text {-value }\end{array}$ & $\begin{array}{c}\text { Rhinobatos } \\
\text { lentiginosus }\end{array}$ & $\begin{array}{c}\text { Squalus } \\
\text { acanthias }\end{array}$ \\
\hline Cranial depression start & $0.0002^{*}$ & $-27 \pm 7$ & $151 \pm 9$ \\
Cranial depression maximum & $0.0001^{*}$ & $141 \pm 13$ & $288 \pm 9$ \\
Cranial elevation start & $0.0007 *$ & $146 \pm 9$ & $7 \pm 8$ \\
Cranial elevation maximum & $0.0009^{*}$ & $246 \pm 9$ & $146 \pm 13$ \\
Lower jaw depression maximum & 0.5818 & $95 \pm 5$ & $98 \pm 7$ \\
Jaw closure complete & 0.2435 & $159 \pm 7$ & $187 \pm 10$ \\
Upper jaw protrusion start & 0.5568 & $104 \pm 7$ & $103 \pm 7$ \\
Upper jaw protrusion maximum & 0.3591 & $160 \pm 8$ & $167 \pm 8$ \\
Upper jaw retraction end & 0.7787 & $239 \pm 9$ & $165 \pm 11$
\end{tabular}

Values are means \pm S.E.M. (in $\mathrm{ms}$ ) from 42 capture events from 5 $R$. lentiginosus and 6 S. acanthias.

*Significant effects at Bonferroni value of $P=0.005$. transports and occasionally during bite manipulation. The depressor hyomandibularis is active during all bite manipulations and occasionally during the other behaviors. The coracohyomandibularis is usually active during suction capture and suction transport events, occasionally active during compression transport and inactive during manipulation. The coracohyoideus showed activity only occasionally during compression transport, the only behavior in which this muscle was active in the one individual successfully implanted. In addition, the coracomandibularis is active during virtually all behaviors in the two individuals successfully implanted, indicating that it is the primary depressor of the lower jaw. Activity in the depressor hyomandibularis and the coracohyomandibularis lags coracomandibularis activity during suction capture and suction transport in these two individuals. This supports the hypothesis that the coracomandibularis is the primary depressor of the lower jaw.

Table 3. Statistical variables and results of ANOVAs on the motor pattern during suction capture $(C)$, bite manipulation $(M)$, suction transport $(S)$ and compression transport $(T)$ behaviors in Rhinobatos lentiginosus

\begin{tabular}{|c|c|c|c|c|c|c|}
\hline Muscle & Capture & Manipulation & $\begin{array}{l}\text { Suction } \\
\text { transport }\end{array}$ & $\begin{array}{l}\text { Compression } \\
\text { transport }\end{array}$ & $P$-value & SNK \\
\hline \multicolumn{7}{|l|}{ Jaw depressors } \\
\hline Coracomandibularis duration & $139 \pm 18$ & $51 \pm 4$ & $71 \pm 7$ & $40 \pm 8$ & & \\
\hline Depressor mandibularis onset & $\mathrm{NP}$ & $-14 \pm 7$ & NP & $-8 \pm 12$ & 0.7329 & \\
\hline Depressor mandibularis duration & NP & $53 \pm 10$ & NP & $65 \pm 5$ & 0.3950 & \\
\hline Depressor hyomandibularis onset & $81 \pm 23$ & $-21 \pm 14$ & $16 \pm 15$ & $-16 \pm 20$ & $0.0010^{*} \dagger$ & $\mathrm{C}>\mathrm{S}>\mathrm{M}, \mathrm{T}$ \\
\hline Depressor hyomandibularis duration & $54 \pm 6$ & $65 \pm 7$ & $25 \pm 6$ & $68 \pm 13$ & $0.5230 \ddagger$ & \\
\hline \multicolumn{7}{|l|}{ Hyoid depressor } \\
\hline Coracohyoideus onset & NP & NP & NP & $27 \pm 9$ & & \\
\hline Coracohyoideus duration & NP & NP & NP & $26 \pm 8$ & & \\
\hline \multicolumn{7}{|l|}{ Jaw adductor } \\
\hline Preorbitalis duration & $51 \pm 11$ & $214 \pm 16$ & $34 \pm 4$ & $44 \pm 5$ & $0.0001 *,+$ & $\mathrm{M}>\mathrm{C}, \mathrm{S}, \mathrm{T}$ \\
\hline \multicolumn{7}{|l|}{ Jaw elevators } \\
\hline Levator palatoquadrati 1 onset & $-49 \pm 28$ & $-23 \pm 9$ & $-48 \pm 21$ & $-12 \pm 7$ & 0.1110 & \\
\hline Levator palatoquadrati 1 duration & $69 \pm 14$ & $72 \pm 10$ & $53 \pm 22$ & $77 \pm 3$ & 0.9270 & \\
\hline Levator palatoquadrati 2 onset & $207 \pm 17$ & NP & $94 \pm 7$ & NP & $0.0001 *$ & $\mathrm{C}>\mathrm{S}$ \\
\hline Levator palatoquadrati 2 duration & $60 \pm 16$ & NP & $119 \pm 24$ & NP & $0.0001^{*} \ddagger$ & $\mathrm{S}>\mathrm{C}$ \\
\hline Levator hyomandibularis 1 onset & NP & $-6 \pm 15$ & NP & $-13 \pm 14$ & 0.4668 & \\
\hline Levator hyomandibularis 1 duration & NP & $43 \pm 10$ & NP & $73 \pm 9$ & $0.0022 *, \ddagger$ & $\mathrm{T}>\mathrm{M}$ \\
\hline Levator hyomandibularis 2 onset & $200 \pm 20$ & $185 \pm 13$ & $102 \pm 12$ & NP & $0.0001 *$ & $\mathrm{C}, \mathrm{M}>\mathrm{S}$ \\
\hline Levator hyomandibularis 2 duration & $86 \pm 28$ & $60 \pm 12$ & $65 \pm 16$ & NP & 0.4747 & \\
\hline
\end{tabular}

Values are means \pm S.E.M. (in ms) from 30 captures, 28 manipulations, 25 suction transports and 25 compression transports from 5 individuals. Muscle activity was recorded from all 5 individuals except depressor mandibularis (4 individuals), coracomandibularis (2 individuals) and coracohyoideus (1 individual).

Significant behavior, *, and individual, $\ddagger$, effect at Bonferroni value of $P=0.003$; NP, indicates events in which that muscle is not active; SNK, results of Student-Newman-Keuls multiple-comparisons test.

1,2 after a muscle name indicates results for the first and second periods of activity. 
Table 4. Statistical variables and results of the nested ANOVA for the interspecific motor pattern analysis

\begin{tabular}{lccc}
\hline Muscle & $\begin{array}{c}\text { Species } \\
P \text {-value }\end{array}$ & $\begin{array}{c}\text { Rhinobatos } \\
\text { lentiginosus }\end{array}$ & $\begin{array}{c}\text { Squalus } \\
\text { acanthias }\end{array}$ \\
\hline Coracomandibularis onset & 0.1659 & $-17 \pm 2$ & $-13 \pm 4$ \\
Coracomandibularis duration & 0.2229 & $87 \pm 9$ & $119 \pm 8$ \\
Quadratomandibularis onset & 0.9838 & $93 \pm 5$ & $89 \pm 4$ \\
Quadratomandibularis duration & 0.8691 & $105 \pm 11$ & $96 \pm 6$ \\
Preorbitalis onset & 0.6741 & $98 \pm 5$ & $100 \pm 7$ \\
Preorbitalis duration & 0.1954 & $103 \pm 11$ & $93 \pm 8$ \\
Levator palatoquadrati 1 onset & 0.0636 & $-34 \pm 8$ & $14 \pm 14$ \\
Levator palatoquadrati 1 duration & 0.1953 & $67 \pm 7$ & $55 \pm 10$ \\
Levator palatoquadrati 2 onset & 0.3941 & $164 \pm 13$ & $178 \pm 21$ \\
Levator palatoquadrati 2 duration & 0.2443 & $76 \pm 9$ & $69 \pm 20$ \\
Levator hyomandibularis 1 onset & 0.9753 & $-6 \pm 15$ & $-25 \pm 22$ \\
Levator hyomandibularis 1 & 0.2459 & $43 \pm 10$ & $76 \pm 10$ \\
$\quad$ duration & & & \\
Levator hyomandibularis 2 onset & 0.7388 & $187 \pm 9$ & $176 \pm 14$ \\
Levator hyomandibularis 2 & 0.9996 & $71 \pm 9$ & $76 \pm 8$ \\
$\quad$ duration & & &
\end{tabular}

Values are means \pm S.E.M. (in $\mathrm{ms}$ ) from 42 capture events from 5 $R$. lentiginosus and 6 S. acanthias.

There were no significant species differences at Bonferroni value $P=0.003$.

1,2 after a muscle name indicates results for the first and second periods of activity.

No interspecific differences were found in the motor activity of the plesiomorphic cranial muscles of the guitarfish and the spiny dogfish (Table 4).

\section{Discussion \\ Guitarfish feeding mechanism}

Prey capture, bite manipulation and suction transport behaviors in the Atlantic guitarfish are characterized by a common relative pattern of kinematic events. However, many differences were found in the specific timing of the kinematic events among these behaviors. Most of these differences are due to the longer duration of capture than manipulation or transport behaviors, as shown by the delayed onset of kinematic and motor events following the start of lower jaw depression. In contrast, the onset and duration of motor activity in several of the cranial muscles is modulated among the feeding behaviors. A novel compression transport mechanism was found that is strikingly different in both kinematic and motor activity from the other behaviors and has not previously been described in any elasmobranch. A model of jaw mechanics for the guitarfish based on anatomy, kinematics and motor activity during feeding will provide a basis for interpreting the feeding mechanism in batoids. The entire feeding event, encompassing prey capture, manipulation, suction transport and compression transport, is extremely long with a mean duration of $16.24 \mathrm{~s}$ (range $3.38-54.87 \mathrm{~s}, N=5$ ). Note that a brief interval (range $50-150 \mathrm{~ms}$ ) of kinematic and motor inactivity takes place between each of the four behaviors.
Prey capture mechanism

A preparatory phase is often present prior to capturing prey. The only muscle active during this phase is the levator palatoquadrati, indicating that the upper jaw is being retracted (Fig. 8). This preparatory elevation of the upper jaw prior to mouth opening may act to assist in expanding the buccal cavity prior to mouth opening for the generation of suction. Cranial depression takes place prior to this phase and is probably effected by the depressor rostri.

Mouth opening and motor activity in the jaw-opening muscles characterize the expansive phase. Posteroventral depression of the lower jaw by the coracomandibularis initiates mouth opening. Note that the depressor mandibularis is not active during suction capture. Midway through the expansive phase, the hyomandibula is depressed ventrally by the coracohyomandibularis, and occasionally by the depressor hyomandibularis, to expand the orobranchial cavity. This consistent anterior-to-posterior sequence of expansion in the head during feeding is crucial in generating a suction current through the orobranchial cavity (Osse, 1969; Lauder, 1980). Movement of the prey during suction capture occurs during activity in the hyomandibular depressors, supporting their role in orobranchial expansion and in the production of suction. The RSI of -0.11 indicates that the guitarfish uses relatively more suction than ram to capture its prey. This phenomenon of anterior-to-posterior head movements has been reported during aquatic feeding in nearly all lower vertebrates regardless of feeding mechanism (see, for example, Lauder, 1979, 1980; Lauder and Shaffer, 1985, 1993; Ferry-Graham, 1997).

The compressive phase is represented by motor activity in the jaw adductors. Lower jaw elevation and upper jaw protrusion by the quadratomandibularis and preorbitalis muscles close the mouth. Protrusion of the upper jaw appears to be the result of a coordinated effort between these muscles (see section on upper jaw protrusion). The quadratomandibularis is a jaw adductor and therefore not only elevates the lower jaw but also protrudes the upper jaw by pulling the upper jaw ventrally towards the lower jaw. As the preorbitalis pulls the jaws anterodorsally, the upper jaw is protruded and the lower jaw is elevated by the quadratomandibularis until the jaws are completely closed.

The head and jaws are returned to the resting position during the recovery phase. The upper jaw is retracted and the hyomandibula is elevated back towards the cranium by the levator palatoquadrati and levator hyomandibularis respectively. Hyomandibular elevation also elevates the jaws through the mandibular-hyomandibula articulation. Finally, the cranium is elevated to the resting position by the epaxialis and the levator rostri. The mean duration of suction capture from the start of lower jaw depression to the end of upper jaw retraction is $274 \pm 15 \mathrm{~ms}(N=5)$.

\section{Bite manipulation mechanism}

Although the mechanics of bite manipulation is similar to that of suction capture, there are several differences that distinguish this behavior from the others (Fig. 9). The prey has already been 
A

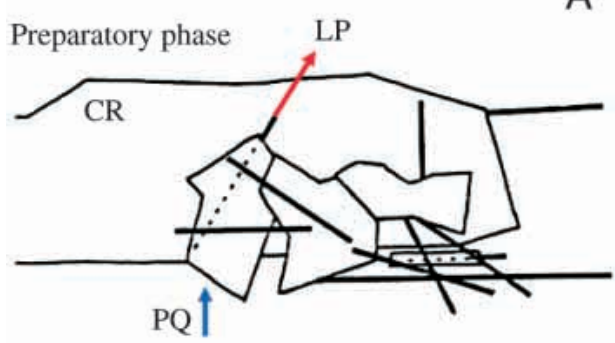

Expansive phase
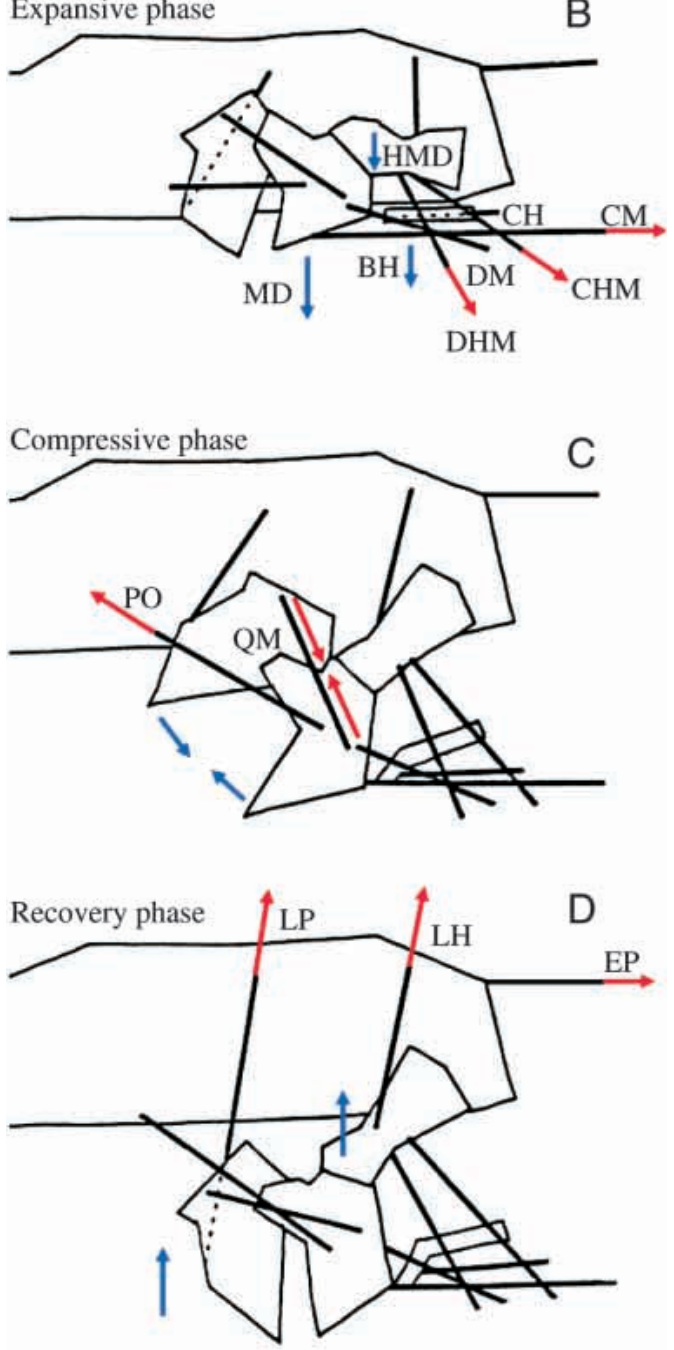

Fig. 8. Schematic diagram of the functional components involved in jaw protrusion and jaw retraction during suction capture. (A) Upper jaw retraction during the preparatory phase. (B) Lower jaw and hyomandibular depression during the expansive phase. (C) Upper jaw protrusion and lower jaw elevation during the compressive phase. Note that the prey (not shown for clarity) has disappeared into the pharyngeal region by the end of this phase. (D) Hyomandibula, upper jaw and lower jaw retraction during the recovery phase. Solid black lines represent muscles, with red arrows indicating their direction of action. Open elements represent skeletal elements, with the direction of movement indicated by blue arrows. Abbreviations as in Figs 2, 4 and 6. captured and is contained between the jaws at the start of bite manipulation. The depressor mandibularis assists the coracomandibularis in depressing the lower jaw. The depressor mandibularis is active only during the compressive behaviors (bite manipulation and compression transport) but not during the suction behaviors (suction capture and suction transport). It may be that depression of the mandible by two muscles rather than just one may allow fine adjustments in lower jaw depression to be made. The depressor mandibularis pulls the proximal end of the lower jaw posteriorly while the coracomandibularis pulls the medial end of the lower jaw posteriorly, and together they may act to open the mouth widely to dislodge the prey from the teeth prior to further processing. Note that no suction inflow is produced and that the prey remains suspended between the jaws until the jaws close onto the prey at the end of the compressive phase. The coracohyomandibularis is not active during manipulation, supporting the hypothesis that it may be critical in the production of suction.

Elevation of the upper jaw by the levator palatoquadrati during the expansive phase may also act to dislodge the upper jaw from the prey prior to re-biting it. Co-activation of the hyomandibular depressors with their antagonist, the levator hyomandibularis, often occurs during the expansive phase. This co-activation of antagonist muscles may act to restrict lower jaw depression or to stabilize the lower jaw while the upper jaw is being elevated. As a result, the jaws can be freed from the prey, yet still allow the lower jaw to partially surround the prey. This may act to position the lower jaw better near the prey in preparation for the bite. The absence of co-activation in the hyomandibular antagonists during suction transport supports this conjecture.

One of the most distinguishing characters of bite manipulation is the exceptionally long duration of activity in the quadratomandibularis and preorbitalis muscles. Activity in these two muscles begin with the compressive phase and extends until well after the recovery period has ended. In contrast, during the other behaviors, these two muscles are active only during the compressive phase. This sustained activity in the jaw-closing muscles suggests that the guitarfish is continuing to bite onto the prey until well after the jaws have closed completely. This prolonged biting activity may be a mechanism to crush or reduce hard-shelled prey prior to swallowing. The mean duration of bite manipulation from the start of lower jaw depression to the end of upper jaw retraction is $247 \pm 21 \mathrm{~ms}(N=5)$.

\section{Suction transport mechanism}

The suction transport mechanism is very similar to that of suction capture, except that it has a shorter duration and the prey is contained between the jaws at the start of this behavior (Fig. 10). As in bite manipulation, upper jaw elevation during the preparatory phase may act to dislodge the upper jaw from the prey prior to transport or may assist in expanding the buccal cavity prior to mouth opening for the generation of suction. As in suction capture, prey movement occurs during activity in the coracohyomandibularis muscle, again indicating the importance of hyomandibular depression in generating suction (Osse, 1969; Lauder, 1979, 1980; Reilly and Lauder, 1992). The 
prey is drawn into the mouth earlier during suction transport than during suction capture. This is probably due to the suction inflow reaching the prey sooner, since it is already between the jaws at the beginning of suction transport. The mean duration of suction prey transport from the start of lower jaw depression to the end of upper jaw retraction is $198 \pm 3 \mathrm{~ms}(N=5)$.
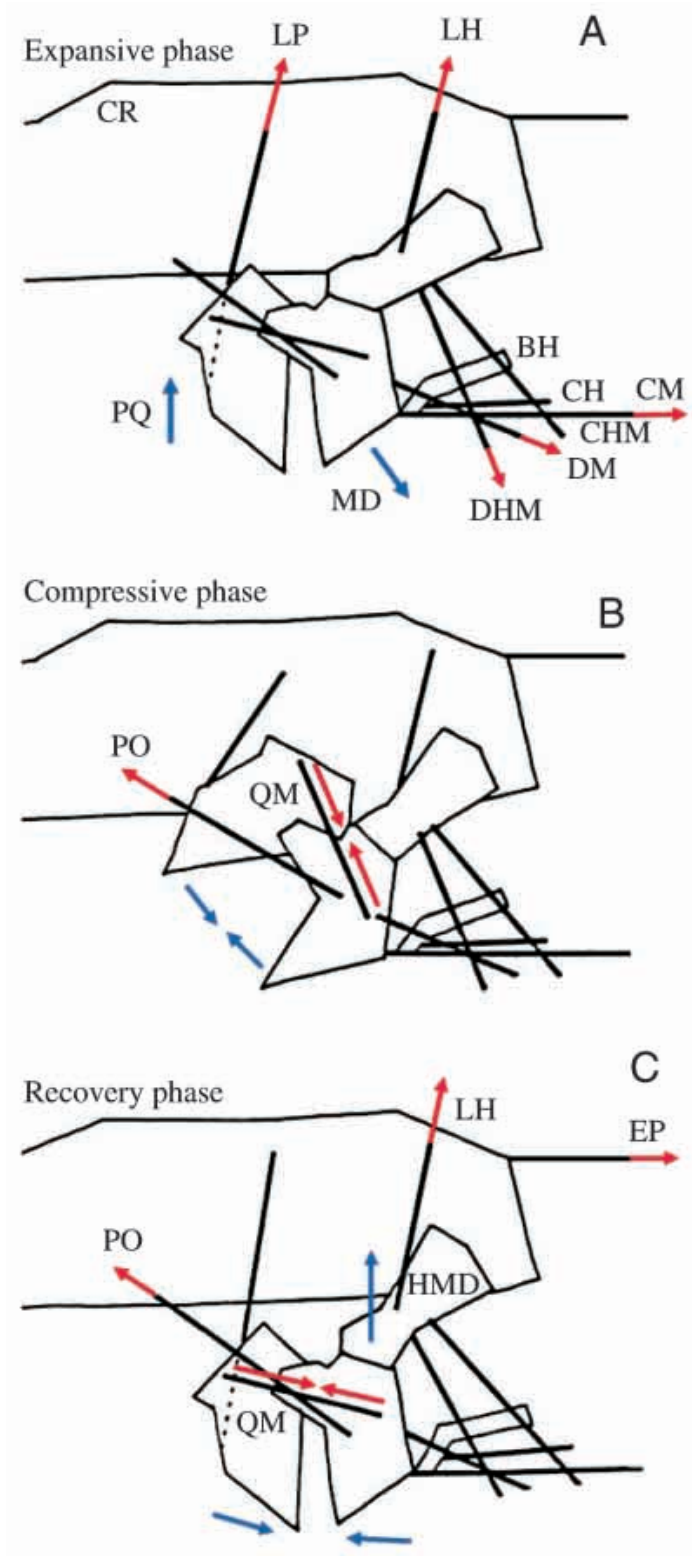

Fig. 9. Schematic diagram of the functional components involved in jaw protrusion and jaw retraction during bite manipulation. Note that the jaws are not fully retracted at the start of this behavior since the prey (not shown for clarity) is contained between the jaws. (A) Lower jaw depression and upper jaw elevation during the expansive phase. Note that the prey remains suspended between the jaws throughout this behavior. The hyomandibula is stabilized by antagonistic activity in its levator and depressor muscles. (B) Upper jaw protrusion and lower jaw elevation during the compressive phase. The jaws continue to adduct onto the prey as the hyomandibula and jaws are retracted during the recovery phase (C). Abbreviations and description as in Fig. 8.
A shorter duration of suction transport than suction capture has also been reported in the spiny dogfish and the leopard shark (Ferry-Graham, 1997; Wilga and Motta, 1998) and is probably due to the prey having already been captured and being contained between the jaws. Thus, the mouth does not have to be open for as long to ensure capture of the prey. Suction transport is also shorter in duration than ram capture in the swell shark (Cephaloscyllium ventriosum; Ferry-Graham, 1997) and the lemon shark (Motta et al. 1997). Suction feeding depends on rapid expansion of the buccal cavity, a mechanism that is faster than simply opening the mouth to swim over the food as in ram feeding. Thus, prey capture, irrespective of the mechanism, is longer than suction transport or compression transport separately (Ferry-Graham, 1997; Motta et al. 1997; Wilga and Motta, 1998), but together these two transport mechanisms can take much longer than prey capture. This may be a general feature of aquatic feeding in lower vertebrates, as Gillis and Lauder (1995) have suggested. Prey transport by suction is widespread in aquatic feeding vertebrates and is observed in sharks, bony fishes and salamanders (Reilly and Lauder, 1992; Gillis and Lauder, 1994, 1995; Motta et al. 1997; Wilga, 1997; Wilga and Motta, 1998).

\section{Compression transport mechanism}

During compression transport, the mouth is not opened and thus an expansive phase is absent. This novel behavior begins with the compressive phase, in which rapid elevation of both the upper and lower jaws from the resting position towards the cranium takes place (Fig. 11). This contrasts sharply with the other feeding behaviors in which the jaws are first depressed and then retracted. Rapid elevation of the jaws and hyomandibula may produce a positive pressure gradient in the buccal cavity that pushes water and prey posteriorly and presumably through the esophagus. Compression transport in the guitarfish may function in a manner similar to the tongue elevation stage during swallowing in terrestrial vertebrates during which the prey is pushed back into the esophagus. Therefore, we hypothesize that the compression transport mechanism acts to push the prey from the pharynx to the esophagus.

The lack of activity in the quadratomandibularis muscle during compression transport is not surprising since the jaws are not opened and do not therefore need to be adducted. Furthermore, the lack of quadratomandibularis muscle activity and the presence of preorbitalis muscle activity during the jaw elevation phase lend support to the role of the preorbitalis in pulling the jaw anterodorsally. The presence of coracohyoideus activity only during compression transport and not during the other behaviors is not understood. It may be that the coracohyoideus functions in compressing the branchial cavity, something that occurs only during compression transport behavior. The coracohyoideus muscle is extremely thin, and the small sample size urges caution in interpreting its motor pattern. In contrast to the other behaviors, the lack of motor activity during the recovery phase during compression transport indicates that depression of the jaws to the resting position is passive and is due to relaxation of the muscles and to release of strain energy in non-muscular tissue. 


\section{C. D. Wilga AND P. J. Motta}

Compression transport is characterized by nearly simultaneous motor activity in all the cranial muscles, except the quadratomandibularis. This type of nearly simultaneous motor activity has not previously been reported for any elasmobranchs studied. However, simultaneous activity in
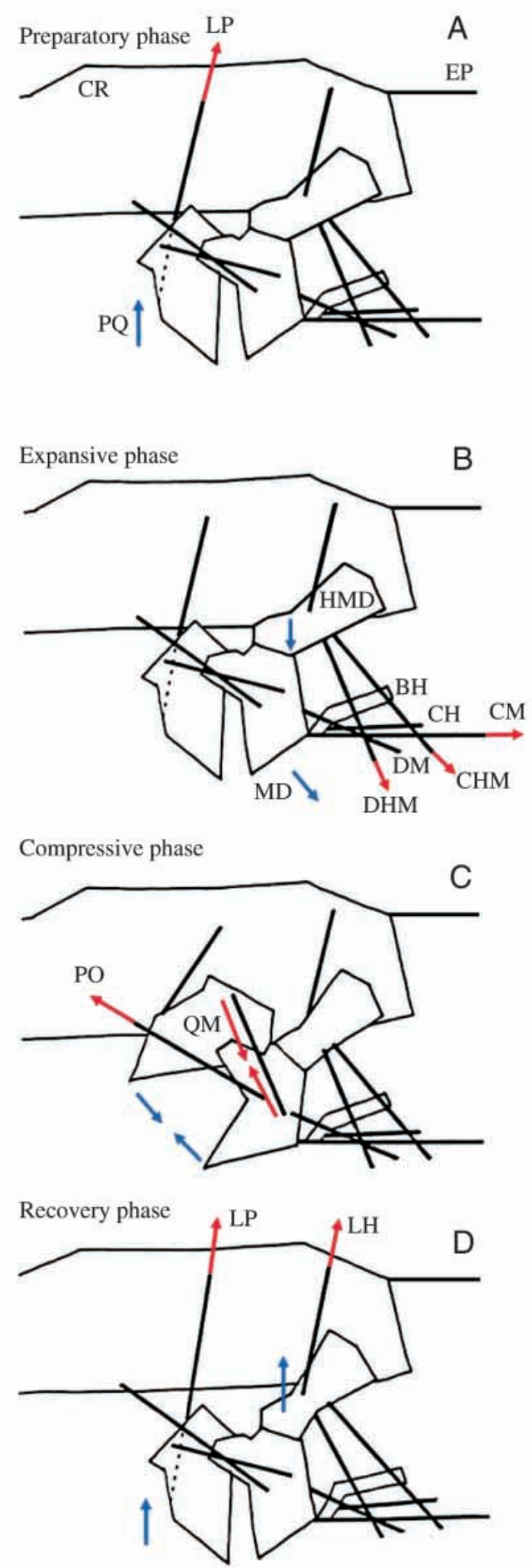

antagonistic jaw muscles is often observed during feeding in teleost fishes (Lauder, 1985). Co-activation of jaw and hyoid depressor and levator muscles may act to stabilize jaw and hyoid movements (Motta et al. 1991, 1997; Wilga and Motta, 1998), particularly during relatively rapid behaviors such as compression transport. The mean duration of compression transport from start of lower jaw elevation to the return of the lower jaws to the resting position is $146 \pm 5 \mathrm{~ms}(N=5)$.

\section{Upper jaw protrusion}

The mechanism of upper jaw protrusion in the guitarfish differs from that described in carcharhinid and squalid sharks (Moss, 1972; Motta et al. 1991, 1997; Wilga, 1997; Wilga and Motta, 1998). In carcharhinid and squaloid sharks, contraction of the preorbitalis places an anteriorly directed force on the posterior portion of the upper jaw, which forces the orbital process of the upper jaw to slide ventrally along ethmoid grooves in the cranium to protrude the upper jaw. In carcharhinid sharks, the levator palatoquadrati muscle is oriented horizontally, is active during upper jaw protrusion during the compressive phase and assists the preorbitalis muscle in protruding the upper jaw (Motta and Wilga, 1995; Motta et al. 1997; Wilga, 1997). The extent of upper jaw protrusion is restricted to the length of the ethmopalatine ligament and muscles interconnecting the upper jaw and the cranium (Motta and Wilga, 1995). In contrast, squalean elasmobranchs, including batoids, have a levator palatoquadrati muscle that is oriented vertically, is active during upper jaw retraction during the recovery or expansive phase and elevates the upper jaw (Wilga, 1997; Wilga and Motta, 1998). Batoids lack orbital articulations between the upper jaw and the cranium that may restrict upper jaw mobility and guide upper jaw protrusion. Therefore, the upper jaw in the guitarfish is free to protrude ventrally towards the substratum and appears to be limited by the extent of lower jaw depression and by the extensibility of the muscles and folds of skin interconnecting the upper jaw and cranium. As a result, the upper jaw can be protruded up to $1.26 \mathrm{~cm}$ in a $62.5 \mathrm{~cm}$ TL guitarfish, $49 \%$ of upper jaw length.

Protrusion of the upper jaw closes the gape by $57 \%$ in the guitarfish. Upper jaw protrusion and lower jaw elevation each traverse half the gape during jaw closure in the guitarfish. In the absence of upper jaw protrusion, the distance that the lower jaw would have to travel to close the gape would nearly double.

Fig. 10. Schematic diagram of the functional components involved in jaw protrusion and jaw retraction during suction transport. Note that the jaws are not fully retracted at the start of this behavior since the prey (not shown for clarity) is contained between the jaws. (A) Upper jaw retraction during the preparatory phase. (B) Lower jaw and hyomandibula depression during the expansive phase. Note that the prey has disappeared into the pharyngeal region by the end of this phase. (C) Upper jaw protrusion and lower jaw elevation during the compressive phase. (D) Hyomandibula, upper jaw and lower jaw retraction during the recovery phase. Abbreviations and description as in Fig. 8. 

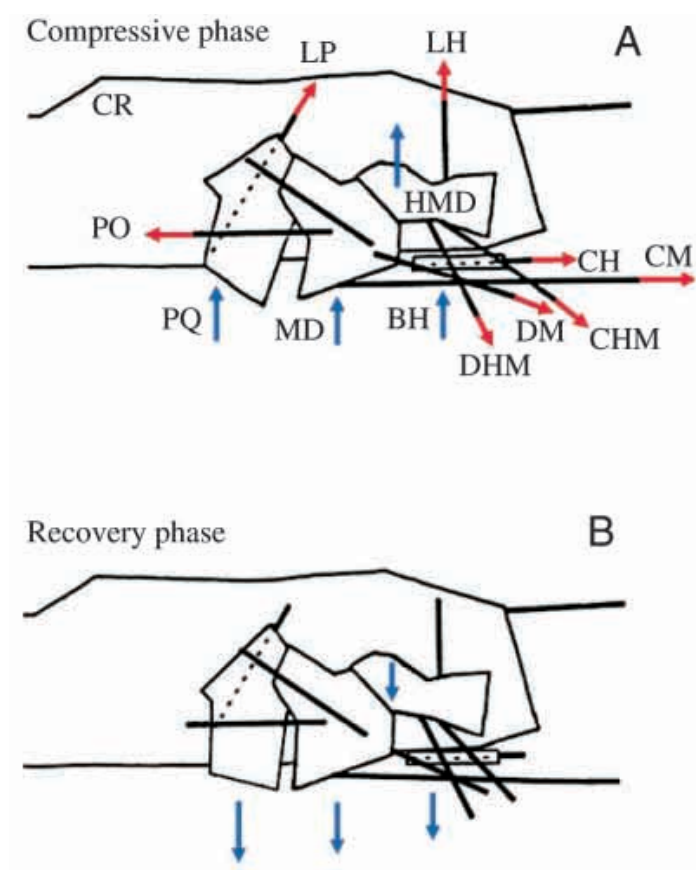

Fig. 11. Schematic diagram of the functional components involved in jaw retraction and jaw depression during compression transport. (A) The upper and lower jaws, hyomandibula and basihyal are retracted during the compressive phase. (B) The jaws and hyomandibula are returned passively to the resting position during the recover phase. Note that this behavior lacks an expansive phase. Solid black lines represent muscles, with red arrows indicating their direction of action. Abbreviations and description as in Fig. 8.

Thus, the time to jaw closure may be decreased by protruding the upper jaw as well as by elevating the lower jaw to close the gape, assuming that velocity remains the same. Upper jaw protrusion in the guitarfish appears to enable more efficient manipulation of the prey and allows the jaws to be protruded during feeding and retracted when resting on the substratum. Depression of the entire jaw apparatus towards the prey also decreases the predator-prey distance, which is crucial in capturing elusive prey such as shrimp.

\section{Functional consequences of structural complexity}

The muscular morphology of the cranium in batoids is considerably more complex than that in sharks (Miyake et al. 1992; Miyake and McEachran, 1991; Motta and Wilga, 1995; McEachran et al. 1996; Wilga, 1997). In elasmobranchs, the embryonic mandibular muscle plate gives rise to the levator palatoquadrati, the quadratomandibularis and the preorbitalis muscles, the hyoid muscle plate gives rise to the levator hyomandibularis muscle, and the hypobranchial muscle plate gives rise to the coracomandibularis, coracohyoideus and coracoarcualis muscles (Miyake et al. 1992). In addition to the muscles listed above, batoids have evolved several muscles that are lacking in sharks. The hyoid muscle plate also gives rise to the depressor mandibularis, the depressor hyomandibularis, the depressor rostri and the levator rostri muscles, and the hypobranchial muscle plate also gives rise to the coracohyomandibularis muscle (Miyake et al. 1992; T. Miyake, personal communication).

We propose that the decoupling of the upper jaw from the cranium, the breaking up of the hyoid arch (separation of the ceratohyal-basihyal elements from the hyomandibula) and the duplication of muscles in the Atlantic guitarfish, and presumably in all batoids, has resulted in increased functional versatility of the feeding apparatus in batoids compared with sharks. As a consequence of the disarticulation of the hyoid arch in batoids, the hyomandibula is free to move independently of the basihyal and has acquired muscular connections to its ventral surface, which are lacking in sharks. This is supported by the independent activity of the muscles controlling the hyomandibula and basihyal across feeding behaviors in the guitarfish (refer to Fig. 6). Depression of the hyomandibula directly by muscles assists in depression of the mandibular arch, which in turn expands the buccal cavity. In contrast, depression of the basihyal has little or no effect on the jaws. The decoupling of the basihyal from the jaws and hyomandibula in batoids allows the branchial cavity to be moved independently of the jaws. This may enable independent respiratory movements to take place simultaneously with extensive processing of the prey during feeding, which may last up to $60 \mathrm{~s}$.

Batoids also possess a novel mandibular depression mechanism through the depressor mandibularis muscle, which assists the ancestral coracomandibularis mechanism. The depressor mandibularis and the coracomandibularis muscles are derived from different embryological muscle plates (Miyake $e t$ al. 1992) and are not developmentally or functionally linked. The two mechanisms are independently active and are modulated during different feeding behaviors in the guitarfish. The coracomandibularis is active during all feeding behaviors in the guitarfish, as well as in sharks. In contrast, the depressor mandibularis is active only during bite manipulation and compression transport. Like the second novel mechanism of mandibular depression in lungfish and salamanders, the second biomechanical system has been added to the ancestral jawopening system without modification of the original system (Lauder and Shaffer, 1993).

The biomechanical mechanism for mouth opening by the sternohyoideus muscle (coracohyoideus and coracoarcualis of elasmobranchs; Winterbottom, 1974)-ceratohyal-mandible coupling, is present in nearly all lower vertebrate clades, including taxa as diverse as bony fish, coelacanths and salamanders (Lauder and Shaffer, 1993; Motta et al. 1991, 1997). However, in the guitarfish, the only muscle that is consistently active during the entire period of mouth opening in all feeding behaviors is the coracomandibularis muscle (geniohyoideus proper of bony fishes and salamanders; Winterbottom, 1974). Furthermore, the decoupling of the ceratohyal-basihyal element from the jaws in batoids precludes the coracohyoideus-coracoarcualis (sternohyoideus) mechanism from opening the mouth. However, the coracohyomandibularis, one of the derived muscles in batoids, arises from the embryonic rectus cervicus muscle along with the coracohyoideus and coracoarcualis muscles and inserts onto the 
hyomandibula (Miyake et al. 1992). Hyomandibular depression by the coracohyomandibularis may assist indirectly in depressing the jaws in the guitarfish; however, the coracohyomandibularis is active only during the latter half of mandibular depression and is not active in all feeding behaviors. Thus, the biomechanical mechanism for mouth opening by the rectus cervicus muscle present in bony fishes (commonly referred to as the sternohyoideus) and salamanders is not necessary to depress the lower jaw. Instead, a derivative of the rectus cervicus, and not the rectus cervicus itself, may assist in indirectly opening the mouth by depressing the hyomandibula during some feeding behaviors.

\section{Conservation of the feeding mechanism}

Batoids are regarded as highly modified squalean sharks in recent phylogenetic studies of elasmobranch evolution (Shirai, 1996; McEachran et al. 1996; DE Carvalho, 1996). Therefore, the question of whether the mechanics of the musculoskeletal apparatus in batoids is conserved or derived from that in squalean sharks is of great interest to evolutionary biologists. In this case, no interspecific differences were found in the motor activity of the plesiomorphic cranial muscles of the guitarfish and the spiny dogfish. Despite the skeletal modifications and the development of additional derived musculature in batoids, the motor pattern in the plesiomorphic muscles of the feeding apparatus is conserved in relatively derived squalean taxa, such as the guitarfish. The only kinematic difference found in the interspecific analysis was restricted to cranial movements. The guitarfish depresses it's cranium at the beginning of the strike, while the spiny dogfish elevates it. This is probably due to the differences in the attack behavior between these two species: the guitarfish uses its rostrum to immobilize the prey against the substratum and to block the escape route, a behavior not observed in the more pelagic foraging dogfish (Wilga and Motta, 1998).

All the plesiomorphic muscles except for the levator palatoquadrati show a similar motor pattern during feeding in the lemon shark, spiny dogfish, bonnethead shark and guitarfish (Motta et al. 1997; Wilga, 1997). The levator palatoquadrati has a derived morphology in both the bonnethead shark and the lemon shark and acts to protrude the upper jaw rather than to retract it, as in the spiny dogfish and the guitarfish (Motta et al. 1997; Wilga and Motta, 1998). In both the spiny dogfish and the guitarfish, the levator palatoquadrati and levator hyomandibularis are modulated among feeding behaviors. In contrast, in the lemon shark and the bonnethead shark, these muscles are active in the same relative pattern in all the feeding behaviors examined (Motta et al. 1997; Wilga and Motta, 1998).

The basic kinematic feeding sequence, composed of lower jaw depression, then upper jaw protrusion and lower jaw elevation, followed by hyoid depression and upper jaw retraction, reported in previous studies of shark feeding is conserved in the guitarfish (Tricas and McCosker, 1984; Frazzetta and Prange, 1987; Motta et al. 1991, 1997; Ferry-
Graham, 1997; Wilga, 1997; Wilga and Motta, 1998). Whether the cranium is first elevated or depressed appears to depend on the foraging ecology. Benthic-feeding elasmobranchs appear to depress the head first, while pelagic-feeding elasmobranchs appear to elevate the head first (Tricas and McCosker, 1984; Frazzetta and Prange, 1987; Motta et al. 1991, 1997; FerryGraham, 1997; Wilga, 1997; Wilga and Motta, 1998).

The expansive phase is longer than the compressive phase in the guitarfish, as is also reported in sharks (Ferry-Graham, 1997; Motta et al. 1997; Wilga, 1997; Wilga and Motta, 1998). This is in contrast to teleosts, salamanders and aquatic turtles, in which the opening phase is more rapid than the closing phase (Lauder, 1985; Shaffer and Lauder, 1985; Lauder and Prendergast, 1992; Reilly and Lauder, 1992; Gillis and Lauder, 1994; Lauder and Reilly, 1994). The expansive phase is longer than the compressive phase, regardless of mechanism (ram or suction), in elasmobranchs and, therefore, does not appear to be connected to suction feeding performance.

The contrast in the length of the expansive phase between teleosts and elasmobranchs may be attributed to differences in the upper jaw protrusion mechanism. Protrusion of the upper jaw occurs during the compressive phase in elasmobranchs and assists elevation of the lower jaw in reducing the gape. However, in teleosts, upper jaw protrusion is mechanically linked to lower jaw depression and functions during the expansive phase. Thus, the upper jaw is being protruded during mouth opening in teleosts and during mouth closing in elasmobranchs and this may shorten the phase in which it is active by reducing the gape.

In summary, the kinematics and motor pattern during prey capture, bite manipulation and suction transport share a similar relative sequence in the guitarfish, but the behaviors are distinguished by variation in the specific timing, activation or duration of muscle activity. A novel compression transport behavior was observed that is markedly different from the other behaviors. The mechanism of upper jaw protrusion in the guitarfish differs from that described in sharks. However, the function and motor pattern in the plesiomorphic muscles of the guitarfish and the spiny dogfish are similar, a condition presumably due to their shared ancestral morphology. Modulation of motor activity in the jaw and hyoid depressor muscles during feeding in the guitarfish may be a consequence of the duplication of muscles and of the decoupling of the jaws and hyoid apparatus in batoids.

The authors gratefully acknowledge the contributions of time, materials and assistance provided by Peter Wainwright, Robert Hueter, Charles Manire, Carl Leur, Enric Cortes, John Tyminski, Heike Keiithen, Jan Keiser, Kristine Lee, Samantha Koelsch, Karen Overholtzer, Mike Robinson, Bruce Carlson, Caroline Campbell, Jason Godin, Dawna Briner and David MacDuffee. Mote Marine Laboratory and the University of South Florida provided facilities and equipment. This project was supported by an NSF Ford Foundation Predoctoral Fellowship, a Mote Marine Laboratory and University of South Florida Graduate Fellowship in Elasmobranch Biology 


\section{Guitarfish feeding mechanism 3183}

and a Sigmi Xi Grant to C.D.W. Equipment used in this research was supported by National Science Foundation grant DEB 9117371 to P.J.M. We thank Steve Norton, Eliot Drucker, Lara Ferry-Graham, Alice Gibb and two anonymous reviewers for their comments on improving the manuscript.

\section{References}

CARroll, R. L. (1988). Vertebrate Paleontology and Evolution. New York: Freeman and Co.

Compagno, L. J. V. (1977). Phyletic relationships of living sharks and rays. Am. Zool. 17, 303-322.

CooK, A. (1996). Ontogeny of feeding morphology and kinematics in juvenile fishes: a case study of the cottid fish Clinocottus analis. J. exp. Biol. 199, 1961-1971.

DAnIEL, J. F. (1922). The Elasmobranch Fishes. Berkeley, CA: University of California Press.

DE CARVAlHo, M. R. (1996). Higher-level elasmobranch phylogeny, basal squaleans and paraphyly. In Interrelationships of Fishes (ed. M. Stiassney, L. Parenti and D. Johnson), pp. 35-62. New York: Academic Press.

Edgeworth, F. H. (1935). Cranial Muscles of Vertebrates. Cambridge: Cambridge University Press.

Ferry-Graham, L. A. (1997). Feeding kinematics of juvenile swellsharks, Cephaloscyllium ventriosum. J. exp. Biol. 200, 1255-1269.

FrazZETTA, T. H. (1988). The mechanics of cutting and the form of shark teeth (Chandrichthyes, Elasmobranchii). Zoomorphology 108, 93-107.

FrazZETTA, T. H. (1994). Feeding mechanisms in sharks and other elasmobranchs. Adv. comp. env. Physiol. 18, 31-57.

Frazzetta, T. H. And Prange, C. D. (1987). Movements of cephalic components during feeding in some requiem sharks (Carcharhiniformes: Carcharhinidae). Copeia 1987, 979-993.

Gillis, G. B. AND LAUdER, G. V. (1994). Aquatic prey transport and the comparative kinematics of Ambystoma tigrinum feeding behaviors. J. exp. Biol. 187, 159-179.

Gillis, G. B. AND Lauder, G. V. (1995). Kinematics of feeding in bluegill sunfish: is there a general distinction between aquatic capture and transport behaviors? J. exp. Biol. 198, 709-720.

GREGORY, W. K. (1904). The relations of the visceral arches to the chondrocranium. Biol. Bull. mar. biol. Lab., Woods Hole 7, 55-69.

Hicks, C. R. (1982). Fundamental Concepts in the Design of Experiments. Forth Worth: Saunders College Publishing.

LAUDER, G. V. (1979). Feeding mechanics in primitive teleosts and in the halecomorph fish Amia calva. J. Zool., Lond. 187, 543-578.

LAUdER, G. V. (1980). Hydrodynamics of prey capture by teleost fishes. In Biofluid Mechanics (ed. D. J. Schneck), pp. 161-181. New York: Plenum Press.

LAUDER, G. V. (1985). Aquatic feeding in lower vertebrates. In Functional Vertebrate Morphology (ed. M. Hildebrand, D. M. Bramble, K. F. Liem and D. B. Wake), pp. 210-229. Cambridge: Harvard University Press.

Lauder, G. V. And Prendergast, T. (1992). Kinematics of aquatic prey capture in the snapping turtle Chelydra serpentina. J. exp. Biol. 164, 55-78.

Lauder, G. V. AND Reilly, S. M. (1994). Amphibian feeding behavior: comparative biomechanics and evolution. In Biomechanics of Feeding in Vertebrates (ed. V. Bels, M. Chardon and P. Vandewalle), pp. 163-195. Berlin: Springer-Verlag.
LAUDER, G. V. AND SHAFFER, H. B. (1985). Functional morphology of the feeding mechanism in aquatic ambystomatid salamanders. $J$. Morph. 185, 297-326.

LAUDER, G. V. AND SHAFFER, H. B. (1993). Design of feeding systems in aquatic vertebrates: major patterns and their evolutionary implications. In The Skull: Functional and Evolutionary Mechanisms, vol. 3 (ed. J. Hanken and B. K. Hall), pp. 113-149. Chicago: University of Chicago Press.

LIEM, K. F. (1978). Modulatory multiplicity in the functional repertoire of the feeding mechanisms in cichlids. I. Piscivores. $J$. Morph. 158, 323-360.

LUTHER, A. (1909). Untersuchungen uber die vom N. trigeminus innervierte Muskulatur der Selachier (Haie und Rochen) unter Berucksichtigung ihrer Beziehungen zu benachbarten Organen. Acta Soc. Sci. Fenn. 36, 1-176.

MaISeY, J. G. (1980). An evaluation of jaw suspension in sharks. Am. Mus. Nov. 2706, 1-17.

MARION, G. E. (1905). Mandibular and pharyngeal muscles of Acanthias and Raia. Am. Nat. 39, 891-920.

McEachran, J. D., Dunn, K. A. And Miyake, T. (1996). Interrelationships of the batoid fishes (Chondrichthyes: Batoidea). In Interrelationships of Fishes (ed. M. Stiassney, L. Parenti and D. Johnson), pp. 63-84. New York: Academic Press.

MiyaKe, T. AND McEachran, J. D. (1991). The morphology and evolution of the ventral gill arch skeleton in batoid fishes (Chondrichthyes: Batoidea). Zool. J. Linn. Soc. 102, 75-100.

MiYaKe, T., McEachran, J. D. AND Hall, B. K. (1992). Edgeworth's legacy of cranial muscle development with an analysis of muscles in the ventral gill arch region of batoid fishes (Chondrichthyes: Batoidea). J. Morph. 212, 213-256.

Moss, S. A. (1972). The feeding mechanism of sharks of the family Carcharhinidae. J. Zool., Lond. 167, 423-436.

Moss, S. A. (1977). Feeding mechanisms in sharks. Am. Zool. 17, 355-364.

Motta, P. J., Tricas, T. C., Hueter, R. E. and Summers, A. P. (1991). Feeding mechanics and functional morphology of the jaws of the lemon shark Negaprion brevirostris. J. exp. Biol. 200, 2765-2780.

Motta, P. J., Hueter, R. E. And Tricas, T. C. (1997). An electromyographic analysis of the biting mechanisms of the lemon shark, Negaprion brevirostris: functional and evolutionary implications. J. Morph. 210, 55-69.

Motta, P. J. And Wilga, C. D. (1995). Anatomy of the feeding apparatus of the lemon shark, Negaprion brevirostris. J. Morph. 226, 309-329.

Norton, S. F. And Brainerd, E. L. (1993). Convergence in the feeding mechanics of ecomorphologically similar species in the Centrarchidae and Cichlidae. J. exp. Biol. 176, 11-29.

OsSE, J. W. M. (1969). Functional morphology of the head of the perch (Perca fluviatilis L.): an electromyographic study. Neth. J. Zool. 19, 289-392.

Reilly, S. M. AND Lauder, G. V. (1992). Morphology, behavior and evolution: comparative kinematics of aquatic feeding in salamanders. Brain Behav. Evol. 40, 182-196.

ShafFer, H. B. AND LAUder, G. V. (1985). Aquatic prey capture in Ambyslomatid Salamanders: Patterns of variation in muscle activity. J. Morphol. 183, 273-284.

SHIRAI, S. (1996). Phylogenetic interrelationships of neoselachians (Chondrichthyes: Euselachii). In Interrelationships of Fishes (ed. M. Stiassney, L. Parenti and D. Johnson), pp. 9-34. New York: Academic Press. 


\section{C. D. Wilga And P. J. Motta}

Tricas, T. C. AND McCosker, J. E. (1984). Predatory behavior of the white shark (Carcharodon carcharias), with notes on its biology. Proc. Calif. Acad. Sci. 43, 221-238.

WiLGA, C. D. (1997). Evolution of feeding mechanisms in elasmobranchs: A functional morphological approach. $\mathrm{PhD}$ thesis, University of South Florida.
Wilga, C. D. AND MotTA, P. J. (1998). Conservation and variation in the feeding mechanism of the spiny dogfish Squalus acanthias. J. exp. Biol. 201, 1345-1358.

Winterbottom, R. (1974). A descriptive synonomy of the striated muscles of the Teleostei. Proc. Acad. nat. Sci. Philad. 125, 225-317. 